\title{
The Observed Wander of the Natural Frequencies in a Structure
}

\author{
by John F. Clinton, S. Case Bradford, Thomas H. Heaton, and Javier Favela
}

\begin{abstract}
The Southern California Seismic Network (SCSN) has recently installed seismic stations in two buildings on the Caltech campus (Millikan Library and the Broad Center). Continuous real-time accelerometer data from these structures are now freely available to the community. This dataset provides a new opportunity to observe, and better understand, the variances in the primary dynamic property of a building system, its natural frequencies. Historical data (triggered strong-motion records, ambient and forced vibration tests) from the well-studied Millikan Library show dramatic decreases in natural frequencies, attributed mainly to moderately large local earthquakes. The current forced vibration east-west fundamental frequency is $22 \%$ lower than that originally measured in 1968. Analysis of the new continuous data stream allows the examination of other previously unrecognized sources of measurable change in the fundamental frequencies, such as weather (wind, rain, and temperature), as well as nonlinear building vibrations from small local and moderate regional earthquakes. Understanding these nonlinear shifts is one of the long-term goals of real-time building instrumentation and is critical if these systems are to be used as a postearthquake damage assessment tool.
\end{abstract}

\section{Introduction}

The past few years have seen a proliferation of real-time structural monitoring testbeds. Analysis of the resulting data is leading toward a better understanding of building response. It is well known that natural frequencies of a soilstructural system have nonlinear variations under different levels of excitation (Kuroiwa, 1967; Foutch, 1976; Luco et al., 1986), and current research at the California Institute of Technology (Caltech) into ambient, forced (Bradford et al., 2004), and earthquake vibration analysis of large concrete buildings, concrete dams (Alves and Hall, 2003), and woodframe buildings (Camelo, 2003) indicates that during small shaking events, there is a measurable change in recorded natural frequencies of all these types of structures. In the case of wood-frame structures, natural frequencies may be reduced by a factor of two during stronger shaking, even without identifiable structural damage (Camelo, 2003). This nonlinear structural softening is not well characterized or understood and needs to be accounted for if real-time building monitoring is to be used effectively as a postearthquake damage assessment tool.

This article attempts to document the amount of frequency shifting in the instrumented large structures at the Caltech campus, the Robert A. Millikan Library, and the Broad Center. The current state of instrumentation on campus is described, and the observed changes in fundamental frequencies are correlated with weather, earthquake history, and building usage.

The temporal wandering of the natural frequencies of the
Millikan Library has been documented previously (Kuroiwa, 1967; Trifunac, 1972; Udwadia and Trifunac, 1974; Foutch, 1976; Luco et al., 1987; Chopra, 1995). Since its construction in 1967, a decrease in these resonant frequencies may be observed from yearly forced vibration experiments and from strong-motion records. This frequency drop has been interpreted to be due to a corresponding softening in system stiffness. Recent ambient and forced vibration tests indicate that the fundamental natural frequency of the structure is now approximately $22 \%$ lower in the east-west direction and $12 \%$ lower in the north-south direction than was determined shortly after construction (Kuroiwa, 1967). Strong-motion records indicate that the natural frequencies drop even further during moderately large events. The $M 6.1$ Whittier Narrows Earthquake, with a epicentral location $19 \mathrm{~km}$ from the library, is one example. By comparing the forced vibration measurements prior to the event (Levine et al., 1988) with the coda of the strong-motion records, the building's east-west and north-south natural frequencies are shown to decrease by $17 \%$ and $25 \%$, respectively. The structure recovers stiffness somewhat after a moderately large shaking event, but because of the lack of data in the immediate aftermath of these mainshocks, the recovery time frame cannot be constrained. Further, Kuroiwa (1967) and others noted that the resonant frequencies drop measurably when the applied force during forced vibrations is increased-during construction in 1966 the fundamental east-west frequency dropped 3\% when applied force was increased by a factor of 8 . 
Recent improvements in the quality and quantity of instrumentation in the building and at other sites on the Caltech campus have led to renewed investigation of the structure. Analysis of structural response to previously unrecorded ambient and small-intensity ground motions is now possible.

Data are presented which indicate that not only do the natural frequencies change significantly during strong shaking, as evidenced by analog recordings of large earthquakes in the recent past, but there are also measurable changes in the resonant frequencies of the buildings due to:

- forced vibrations using varying forces

- minor earthquake shaking

- weather conditions (rain and wind events, extremes in temperature)

These last two factors also affect the recently constructed Broad Center on the Caltech campus (the Broad Center has not yet been shaken or subjected to strong earthquake motions).

The lowering of the natural frequencies during transient events in the Millikan Library is likely due to a combination of two mechanisms, a nonlinear softening of the superstructure itself and an interaction of the structure with the surrounding soil. Changes in occupancy usage are also responsible for natural frequency changes. Note that the construction of partition walls for office space in three entire levels during the spring of 2003 coincides with a significant and permanent raising of the natural frequencies (though the magnitude of the change in frequency is difficult to explain considering the relatively small increase in stiffness expected by the addition of the partition walls).

The natural frequency of a structure, as measured by accelerometers on the structure, is a combination of the fundamental fixed-base period of the structure, as well as the rocking and horizontal translation frequencies of the same structure if it moved as a rigid body on the flexible soil (Trifunac, 1999; Trifunac and Ivanovic, 2003). Throughout this article, all references to the natural frequencies of the structure refer to these combined-system frequencies. Note also that, in addition to the differences in amplitude, forced vibration tests differ from ambient and earthquake motions in how energy is imparted to the system. For forced vibration tests, the energy source located on the roof (the shaker) emits a continuous single frequency, and energy flows down the building and out into the half-space. In ambient and earthquake vibrations, scattered energy with highly variable frequency content enters the building from the bottom, travels to the roof, reflects back down, and eventually dissipates into the half-space.

\section{Historical Evidence for Natural Frequency Wandering-Millikan Library}

The Robert A. Millikan Library is located at the center of campus at the California Institute of Technology (see Fig. 1a). It is a nine-story reinforced concrete building with a basement and an enclosed roof (housing air-conditioning equipment), which was completed in 1967. The library is $21.0 \mathrm{~m}$ by $22.9 \mathrm{~m}$ in plan, and it extends $43.9 \mathrm{~m}$ above grade and $48.2 \mathrm{~m}$ above basement level. Interstory heights are all $4.27 \mathrm{~m}$, except for the height between the first and second floors, which is $4.88 \mathrm{~m}$. The roof wall is also $4.88 \mathrm{~m}$. The structural system consists of a moment frame combined with large stiff reinforced concrete shear walls $(30.5 \mathrm{~cm}$ thick) on the east and west sides of the building. These shear walls provide the predominant resistance to lateral forces in the north-south direction. A 30.5-cm-thick reinforced concrete inner core adds stiffness to the building, which along with the concrete moment frame and the bolted precast concrete window/wall panels, provides the lateral stiffness in the east-west direction. The foundation system is composed of a central pad $9.75 \mathrm{~m}$ wide by $1.2 \mathrm{~m}$ deep, which extends across the building to the shear walls on the east and west sides. Two foundation beams ( $2.74 \mathrm{~m}$ wide by $0.61 \mathrm{~m}$ deep) run parallel to the central pad under the north and south wall, respectively. A series of stepped beams transfer loads from these foundation beams to the central pad. More detailed descriptions of the structural system may be found in $\mathrm{Ku}-$ roiwa (1967), Foutch et al. (1975), Foutch (1976), and Luco et al. (1986). The alluvium under the foundation consists of medium to dense sands mixed with gravels, and bedrock lies at a depth of about $275 \mathrm{~m}$. The water table appears to be at about 11 m depth (Kuroiwa, 1967; Luco et al., 1987). Figures $1 \mathrm{~b}$ and $1 \mathrm{c}$ show a north-south cross section and a typical floor plan.

After the 1971 San Fernando Earthquake, cracking and spalling of the concrete slabs located on the ground floor entry plaza were noted (Foutch and Jennings, 1978). Further, horizontal cracks along the pour line in the core shear walls between both the basement and first floor, and first and second floors, have been observed in the emergency staircase in the north-south direction. Access to the east-west sides of the core shear wall is not possible. The steam tunnels that connect various buildings on campus also suffered some minor cracking close to the Library. No further structural damage has been observed in the building.

In 1968, the building was instrumented with two permanent triaxial Teledyne-Geotech RFT-250 accelerometers, located on the roof and basement. A 10-channel Kinemetrics CR-1 strong-motion array was also installed in 1979, with channels on the basement, sixth floor, and roof. These systems have since been superseded by a 24-bit continuously recorded digital triaxial accelerometer, the SCSN station MIK (installed in 2001), on the ninth floor, and a 36-channel 19bit triggered-accelerometer array run by the U.S. Geological Survey (USGS) (installed in 1998), with a minimum of three channels on each floor. A synchronized shaker was permanently installed on the roof of the building in the early 1970s and is still used for forced vibration testing (Hudson, 1962).

Yearly modal analysis of the structure (using temporary deployments of Kinemetrics Ranger SS-1 seismometers) 
during civil engineering classes at Caltech, as well as the triggered event data from the RFT-250 and CR-1 arrays, have provided us with a relatively detailed history of the evolution of the dynamic properties of the building. A summary of the fundamental natural frequencies observed during strong shaking and selected forced vibration tests is presented in Table 1 (a more complete list is in Clinton, 2004).
Figures 2 and 3 present graphical interpretations of Table 1. In Figure 2, the natural frequencies are plotted against the date of the observation. There is a clear trend toward lower natural frequencies as time increases, with major steps occurring during large earthquakes. Figure 3 plots frequency versus the coincident roof acceleration amplitude, on logarithmic axes. There is a clear pattern of frequency dropping

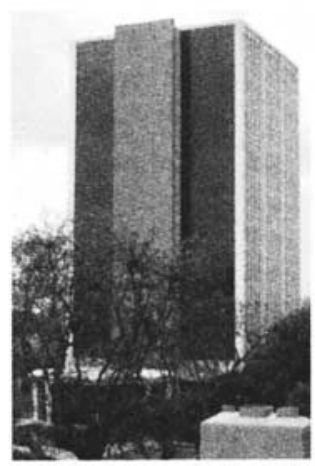

(a) View from NE

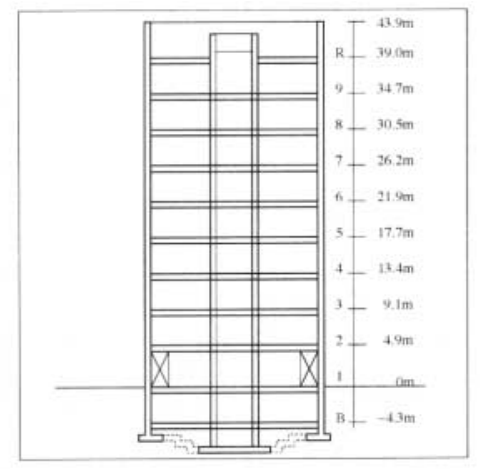

(b) NS Section

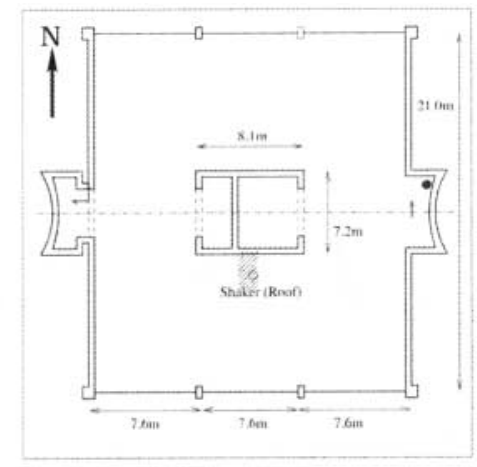

(c) Typical Plan View

Figure 1. Millikan Library. (a) View from the northeast. The two dark walls in the foreground comprise the 30.5 -cm-thick east shear wall, which is somewhat narrower on the ground floor because of walkway openings. The wall panels and concrete moment frame are visible on the north face. (b) North-south section. Walkway openings on the ground floor, which cut through the shear walls, are represented by crosses. (c) Typical plan view. The dark circle is the approximate position of SCSN Station MIK on the ninth floor, the arrows are the approximate positions and orientations of the three USGS channels on each floor (from first floor to roof).

Table 1

Natural Frequencies and Peak Roof Accelerations from Selected Strong-Motion Data and Forced Vibration Experiments*

\begin{tabular}{|c|c|c|c|c|c|c|c|c|}
\hline \multirow[b]{2}{*}{ Event/Test } & \multicolumn{4}{|c|}{ East-West } & \multicolumn{4}{|c|}{ North-South } \\
\hline & $\begin{array}{l}\text { Nat. Freq. } \\
\quad(\mathrm{Hz})\end{array}$ & $\%$ diff1 & $\%$ diff2 & $\begin{array}{l}\mathrm{mx} \text { accn } \\
\left(\mathrm{cm} / \mathrm{sec}^{2}\right)\end{array}$ & $\begin{array}{c}\text { Nat. Freq. } \\
(\mathrm{Hz})\end{array}$ & $\%$ diff1 & $\%$ diff2 & $\begin{array}{l}\mathrm{mx} \text { accn } \\
\left(\mathrm{cm} / \mathrm{sec}^{2}\right)\end{array}$ \\
\hline Forced vibrations, 1967 & 1.45 & - & - & - & 1.90 & - & - & - \\
\hline Lytle Creek, 1970, M 6.3, $\Delta=57$ km & 1.30 & 10.3 & 10.3 & 49 & 1.88 & 1.1 & 1.1 & 34 \\
\hline San Fernando, 1971, M 6.6, $\Delta=31 \mathrm{~km}$ & 1.0 & 31.0 & 31.0 & 306 & 1.64 & 13.7 & 13.7 & 341 \\
\hline Forced vibrations, 1974 & 1.21 & 16.6 & 16.6 & - & 1.77 & 6.8 & 6.8 & - \\
\hline Whittier Narrows, 1987, M 6.1, $\Delta=19$ km & 1.00 & 31.0 & 17.4 & 262 & 1.33 & 30.0 & 24.9 & 534 \\
\hline Forced vibrations, 1988 & 1.18 & 18.6 & 2.5 & - & 1.70 & 10.5 & 4.0 & - \\
\hline Sierra Madre, 1991, M 5.8, $\Delta=18 \mathrm{~km}$ & 0.92 & 36.6 & 22.0 & 246 & 1.39 & 26.8 & 18.2 & 351 \\
\hline Forced vibrations, 1993 & 1.17 & 19.3 & 0.8 & - & 1.69 & 11.1 & 0.6 & - \\
\hline Northridge, 1994, M 6.7, $\Delta=34 \mathrm{~km}$ & 0.94 & 35.2 & 19.7 & 143 & 1.33 & 30.0 & 21.3 & 512 \\
\hline Forced vibrations, 1994 & 1.15 & 20.6 & 1.7 & - & 1.67 & 12.1 & 1.2 & - \\
\hline Forced vibrations, 1995 & 1.15 & 20.6 & 0.0 & - & 1.68 & 11.6 & -0.6 & - \\
\hline Beverly Hills, 2001, M 4.2, $\Delta=26$ km & 1.16 & 20.0 & -0.9 & 9.3 & 1.68 & 11.6 & 0.0 & 11.8 \\
\hline Forced vibrations, 2002, full weights & 1.11 & 23.4 & 3.5 & 3.6 & 1.64 & 13.7 & 2.4 & 8.0 \\
\hline Forced vibrations, 2002, half weights & 1.14 & 21.4 & 0.9 & 1.9 & 1.67 & 12.1 & 0.6 & 4.1 \\
\hline Big Bear, 2003, M 5.4, $\Delta=119 \mathrm{~km}$ & 1.07 & 26.2 & 6.1 & 14.2 & 1.61 & 15.3 & 3.6 & 22.6 \\
\hline Continuous data average, May 2001-Nov. 2003 & 1.19 & - & - & - & 1.72 & - & - & - \\
\hline San Simeon, 2003, M 6.5, $\Delta=323 \mathrm{~km}$ & 1.14 & 21.4 & 0.0 & 20.4 & 1.54 & 18.9 & 7.8 & 14.3 \\
\hline
\end{tabular}

*\% diff 1 is the difference between the recorded frequency and that obtained in the first forced vibration tests (Kuroiwa, 1967); \% diff 2 is the difference between the recorded frequency and that obtained in the most recent forced vibration test prior to the event; Nat. Freq. is natural frequency; mx accn is maximum acceleration. A complete history is presented in Clinton (2004). Note the 1967 entry is representative of the results from all tests from 1967 up to the 1970 Lytle Creek Earthquake; the building was already fully loaded with books. 

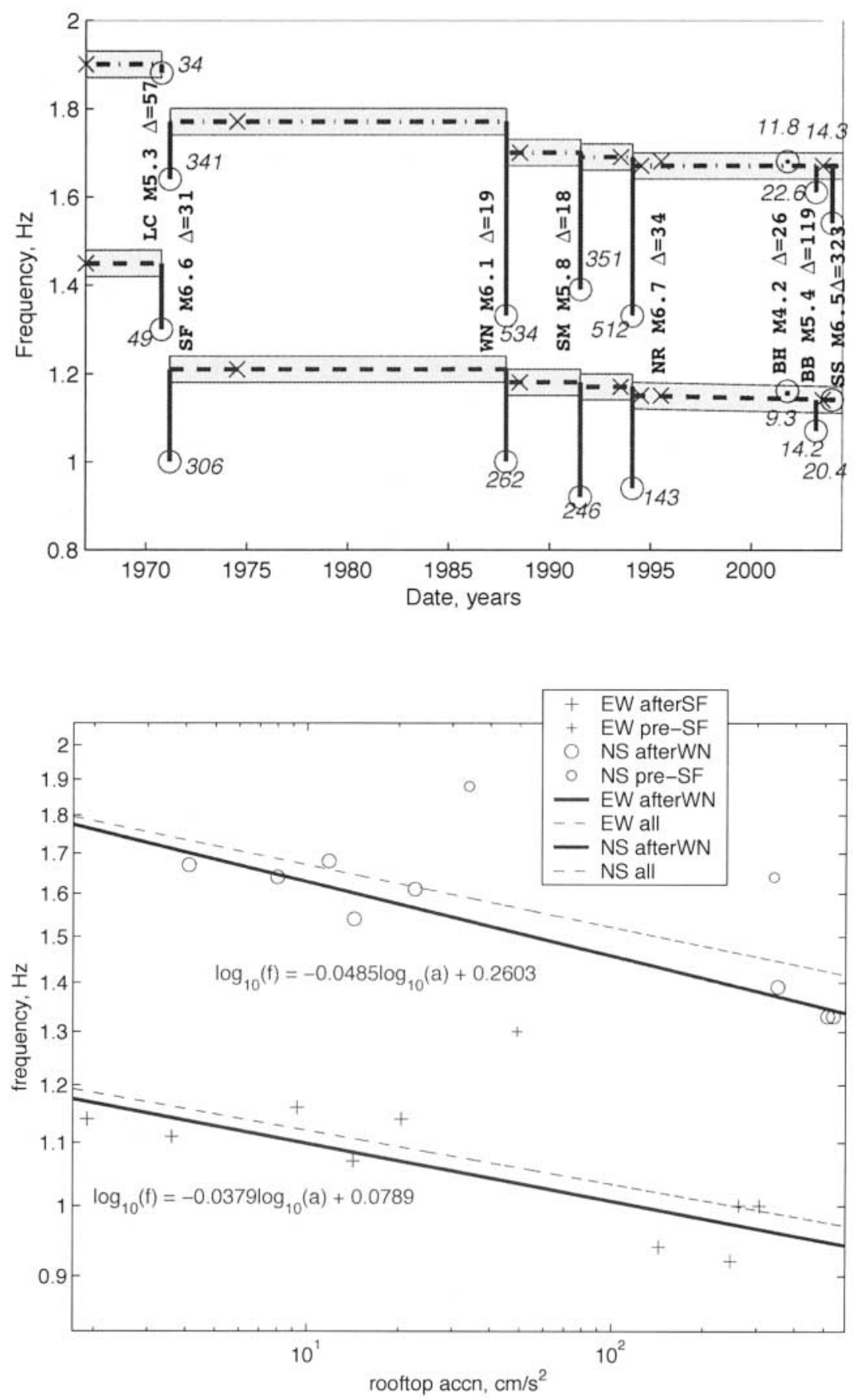

Figure 2. Graphical interpretation of Table 1. Dashed lines are east-west natural frequencies, dashed-dotted lines are north-southnatural frequencies, all from forced vibration testing. Shaded area is the likely region of natural frequencies taking into consideration errors in measurement, caused by unknown shaker weight configuration and weather conditions for each test, and experimental error. Crosses indicate the actual time of a forced vibration measurement. Circles indicate the natural frequency estimated from the strongmotion recording of the event, with the number in italics giving the peak acceleration recorded for the event $\left(\mathrm{cm} / \mathrm{sec}^{2}\right)$.

Figure 3. Graphical interpretation of Table 1 - peak rooftop acceleration (accn) amplitude versus frequency, log scaling. For both eastwest and north-south, the best-fitting leastsquares solution for all the data is plotted in dashed lines. Outlying data from tests and earthquakes prior to main permanent natural frequency shift (pre-Whittier Narrows for north-south; pre-San Fernando for east-west) are removed from dataset for the solid-line regressions, with labeled functional form. with increasing excitation amplitude. The best-fitting line is a good fit to the data, though a very large variance still exists.

Kuroiwa (1967) first observed variation in the natural frequencies, measuring a decrease in natural frequencies proportional to the applied force imparted by the shaker. This has been consistently observed since then. For example, in the tests carried out in July 2002 by Bradford et al. (2004), during shaking with full weights, an east-west natural frequency of $1.11 \mathrm{~Hz}$ was measured, and during shaking with only four side weights, the natural frequency was $1.14 \mathrm{~Hz}$ a difference of $0.03 \mathrm{~Hz}$ or $2.5 \%$. This change in weights corresponds to a factor of nearly 2 difference in the amplitude of the rooftop sinusoidal acceleration, and a factor of 2.23 change in the applied force. Similar changes were observed in the north-south fundamental frequency. Thus, with weight configurations variable in some of the forced tests (and unknown in some cases), this level of variability in reporting of results should be noted. It is assumed that the forced vibration test results in Table 1 are taken with the shaker loaded with half-full weights. The shaded area in Figure 2 is a $\pm 0.03 \mathrm{~Hz}$ error band for the natural frequencies, which reflects both this loading uncertainty and temporal 
fluctuations caused by the changing weather conditions, as discussed in this article.

The natural frequencies from strong shaking are determined from the resonance of the structure (measured at the roof channels) in the immediate aftermath of a large event. This is illustrated in Figure 4, which shows the response of the east-west channels of the CR-1 array at Millikan to the 1987 M 6.1 Whittier Narrows Mainshock (Levine et al., 1988).

Table 1 shows the initial natural frequencies of the building at $1.45 \mathrm{~Hz}$ in the east-west direction and at $1.90 \mathrm{~Hz}$ in the north-south direction. For this initial test, and many subsequent tests, the higher order modes, including the first torsional frequency, are not clearly and unambiguously identified because of the poor signal-to-noise ratio for the recording systems of the time. (SMA-1s, CR-1s, and Ranger SS-1s all have a dynamic range in the order of 3 orders of magnitude $(60 \mathrm{~dB})$, compared with the $144-\mathrm{dB}$ resolution of the 24-bit instruments.)

The recorded history includes four moderately large shaking events, all with roof accelerations of at least 340 $\mathrm{cm} / \mathrm{sec}^{2}$ (over $34 \% \mathrm{~g}$ ). Several smaller events, including the 1970 Lytle Creek Earthquake, and some more recent events recorded on the digital instruments, with accelerations below $50 \mathrm{~cm} / \mathrm{sec}^{2}$, are also included on Table 1 for comparison. During strong motion, the natural frequencies temporarily fall by about $20 \%$. Surprisingly, after each strong-motion event, the structural system stiffens and natural frequencies return to near pre-earthquake levels, usually with a permanent drop in frequency of less than $2.5 \%$. Some events have led to a larger permanent decrease of all subsequent forced vibration resonant frequencies. In the most extreme case, the east-west fundamental frequency dropped permanently by $16.6 \%$ in tests subsequent to the 1971 San Fernando event.

\section{East-West Fundamental Frequency}

In the east-west direction, the lateral forces are primarily resisted by the elevator core and the concrete moment frame (the architectural facade of stiff window frames provide additional stiffness). Table 1 shows that the very first significant earthquake motion (from the 1970 M 5.3 Lytle Creek earthquake, $\Delta=57 \mathrm{~km}$ ), with comparatively small rooftop accelerations of $49 \mathrm{~cm} / \mathrm{sec}^{2}$, resulted in a decrease of $10.3 \%$ in the natural frequency as measured in the strongmotion record. A further softening occurred during the larger magnitude, closer $1971 M 6.6$ San Fernando event $(\Delta=31$ $\mathrm{km}$, peak roof accelerations $=306 \mathrm{~cm} / \mathrm{sec}^{2}$, with the fundamental frequency measured at about $1.0 \mathrm{~Hz}$ during the strong shaking. Subsequent forced vibration tests indicate the frequency dropped permanently by $16.6 \%$, to $1.21 \mathrm{~Hz}$, from these two events. No earthquake recorded since has generated east-west motions that exceeded the velocities and accelerations of the San Fernando event. Correspondingly, subsequent natural frequencies from strong-motion and forced vibration do not show any significant loss of stiffness of the structural system. The most recent east-west natural frequency recorded from forced vibrations is $1.14 \mathrm{~Hz}$ (Bradford et al., 2004). The general mode shape has remained constant throughout the history (Foutch, 1976; Bradford et al., 2004), though the component of rocking in the east-west mode is not well characterized by recent studies, e.g., Bradford et al. (2004), which do not account for rocking at the base of the elevator core, because sensors are located only at the edges of the building. Foutch et al. (1975), using a dense temporary deployment of sensors, shows that the rocking contribution at the base is significant.

\section{North-South Fundamental Frequency}

For the north-south direction, with the lateral resistance provided by the massive shear walls, a different pattern emerges. Very little frequency loss occurs during the Lytle Creek event-even the strong-motion record shows a decrease of only $1.1 \%$. Instead, it is the San Fernando event, with rooftop accelerations of $341 \mathrm{~cm} / \mathrm{sec}^{2}$, that causes the first major frequency drop; natural frequencies from forced vibrations fell from $1.9 \mathrm{~Hz}$ to $1.77 \mathrm{~Hz}$ after the event. Mode shapes before and after the San Fernando event show major differences. This can be illustrated by considering the relative contributions to the displacements at the roof; before the earthquake, less than $3 \%$ of the peak roof displacement is attributed to basement rocking, yet after, and in subsequent tests, approximately $30 \%$ of the roof motion is due to basement rocking (Jennings and Kuroiwa, 1968; Foutch, 1976; Bradford et al., 2004). Another major decrease occurs during the $1987 M 6.1$ Whittier Narrows event $(\Delta=19 \mathrm{~km})$, where the highest rooftop accelerations $\left(534 \mathrm{~cm} / \mathrm{sec}^{2}\right)$ were recorded during the shaking. Figure 2 shows that this event caused the largest intraevent frequency drop (nearly 25\%), with a $4 \%$ permanent decrease in forced frequencies. Subsequent natural frequency measurements from forced vibration tests are relatively constant, and no further softening beyond the $1.33 \mathrm{~Hz}$ recorded in Whittier Narrows occurs during strong motions (including the Northridge Earthquake). The most recent forced north-south natural frequency is $1.67 \mathrm{~Hz}$ (Bradford et al., 2004).

\section{East-West Second Mode Frequency}

At construction, the second east-west mode frequency was determined as $6.2 \mathrm{~Hz}$ (Kuroiwa, 1967) (though it is not clear whether the building had been fully completed at this time; the heavy cladding may not have been added). During the San Fernando event, the frequency dropped to $\sim 4.95 \mathrm{~Hz}$ (McVerry, 1980; Beck and Chan, 1995). Investigations subsequent to this earthquake have indicated the second mode varies from $4.17 \mathrm{~Hz}$ (Beck and Chan, 1995) to $5.35 \mathrm{~Hz}$ (Teledyne-Geotech-West, 1972). The most recent measured forced east-west second modal frequency is $4.93 \mathrm{~Hz}$ (Bradford et al., 2004). 


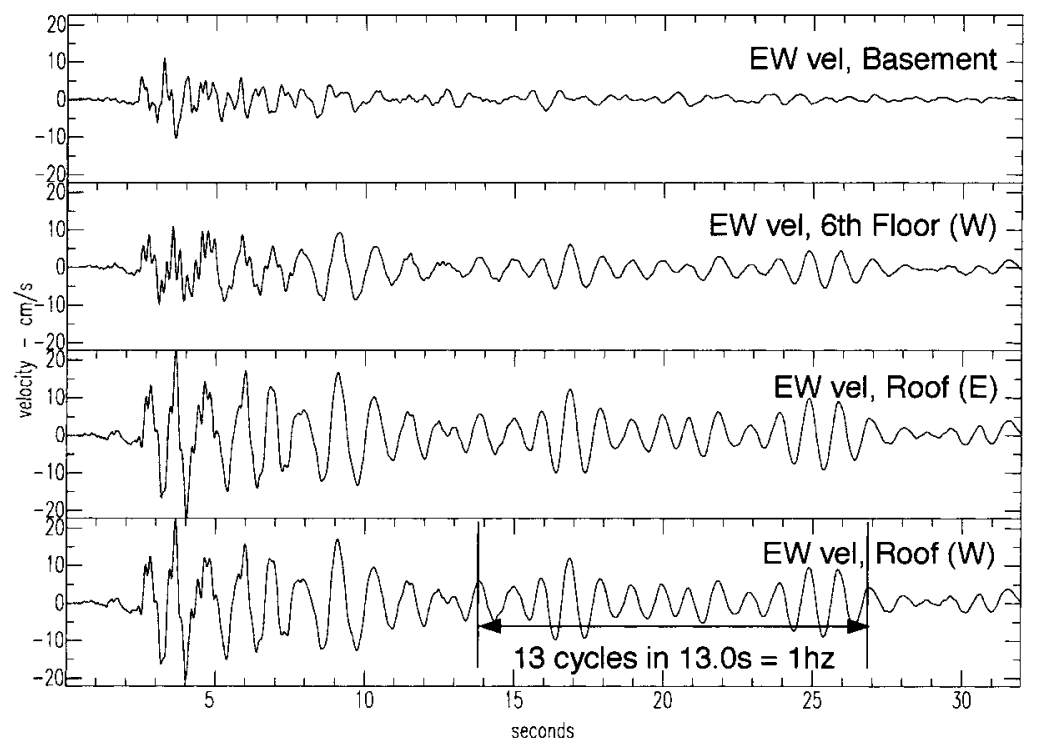

Figure 4. East-west components of CR-1 array in Millikan Library, recorded during the $M 6.1$ Whittier Narrows earthquake $\Delta=19$ $\mathrm{km}$, velocity time series. The top trace is from the basement, the second is from the sixth floor, and the last two are from the roof. The last trace includes a sample of how the fundamental frequency of the building is estimated, after the main energy (seen from the basement trace) has passed.

\section{Response to Small Earthquakes}

Table 1 also contains fundamental frequencies determined from shaking due to the small $M 4.2$ Beverly Hills event $(\Delta=26 \mathrm{~km})$ in September 2001. Even though measured accelerations from the event are about double the accelerations from the sinusoidally excited forced vibration tests, the measured fundamental frequencies are higher than those from forced testing. This may be attributed to changes in the ambient pre-earthquake natural frequency due to climatic changes, and will be discussed in detail later.

The February 2003 M 5.4 Big Bear event $(\Delta=119$ $\mathrm{km}$ ) produced accelerations almost double those from the M 4.2 Beverly Hills event, and yet it had a more significant effect on the fundamental frequencies - the drop in frequency from Big Bear is much greater than double the drop observed in Beverly Hills. This suggests that the relationship between fundamental frequency and acceleration is nonlinear. Further, it is observed that the fundamental frequency during the Big Bear event drops by $6.1 \%$ in the east-west direction, and only $3.6 \%$ in the north-south direction, even though the north-south accelerations are larger. This indicates that the east-west direction is more susceptible to softening under small excitations and that larger motions are required to start significant softening in the north-south direction (the ambient data will corroborate this observation). The response of the library to this earthquake will be studied in more detail.

Figure 3 indicates there is, in general, a linear relationship between the logarithm of the acceleration amplitude and logarithm of the frequency, though the scatter of the data is large, and, at least for the small amplitudes, may be due to the ambient variations in natural frequencies.

\section{The Current System of Instrumentation at Caltech}

Currently, five buildings on the Caltech campus have the real-time telemetry of high-dynamic-range digital instru- mentation. These are the Millikan Library, the Broad Center for the Biological Sciences, the USGS Building at $525 \mathrm{~S}$. Wilson Avenue, the Robinson Building, and the Athenaeum. A dense array at Millikan Library is comprised of triggered digital accelerometers with dial-up data retrieval.

The Caltech Civil Engineering Department operated an older network of analog film-recording SMA-1s at a number of sites on and around the campus, as well as a 12-channel CR-1 at Millikan Library, which had been operational on campus since the 1970s. However, this network has not been maintained since the mid-1990s and is currently not operational.

\section{Millikan Library (MIK, USGS-Caltech Array)}

In January 1998 the USGS and Caltech Civil Engineering Department installed a 36-channel dense network of FBA-11 accelerometers recording triggered event data on two 19-bit Mt. Whitney dataloggers with dial-up data retrieval. A triaxial EpiSensor accelerometer was also installed on the ninth floor of the structure and has been continuously transmitting 24-bit data since February 2001, to the Southern California Earthquake Data Center (SCEDC), as station MIK in the California Integrated Seismic Network (SCSN).

This improved sensor configuration prompted a detailed forced dynamic analysis (using the existing shaker located on the roof), which was performed in the summer of 2002 (Bradford et al., 2004). The results of this study are summarized in Table 2. At the time of the tests, the approximate first mode frequencies during forced vibration (1/2 weights) are $1.14 \mathrm{~Hz}$ for the east-west direction, $1.67 \mathrm{~Hz}$ for the north-south direction, and $2.38 \mathrm{~Hz}$ for the torsional mode.

\section{Broad Center (CBC)}

This is a three story structure with an irregular floor plan and two deep basements (see Fig. 5). It was completed in 
Table 2

Natural Frequencies for the Millikan Library and the Broad Center

\begin{tabular}{lccccccc}
\hline & \multicolumn{3}{c}{ Millikan Library (Hz) } & & \multicolumn{2}{c}{ Broad Center (Hz) } \\
\cline { 2 - 3 } Orientation & First & Second & Third & & First & Second \\
Mode & Mode & & Mode & Mode \\
\hline East-West & $1.14[1.19]$ & 4.93 & 7.83 & & 2.67 & 3.01 \\
North-South & $1.67[1.72]$ & 7.22 & $?$ & & 2.43 & 2.81 \\
Torsional & $2.38[2.46]$ & 6.57 & $?$ & & 3.65 & $?$ \\
\hline
\end{tabular}

Millikan Library frequencies are from forced vibration tests, summer 2002 (Bradford et al. 2004). For the three fundamental frequencies, in parentheses are the 2-year average frequencies from continuous ambient MIK data. Broad Center results are from the ambient vibration data from 14 days of continuous data during February 2003 and are preliminary (in the absence of a forced vibration modal analysis of the structure).

the summer of 2002 and has been instrumented since February 2003. The basements are enclosed by stiff shear walls, and the steel superstructure is braced with stiff unbonded braces in both the north-south and east-west directions.
The building houses a 24-bit SCSN station, recording eight channels of EpiSensor accelerometer data. Three triaxial instruments are installed, all on the plan of the unbonded braced frame-line that is the structural core of the building. Two are located near the northwest intersection of the frame line, one on the first floor, with the other on the roof. The final accelerometer, which only has its horizontal channels logged (the datalogger supports only eight channels of data), is near the southeast intersection of the frame line. All eight channels comprise SCSN station CBC. The instrument layout is illustrated by the schematic in Figure 5c.

In the absence of a forced vibration modal analysis for the building, the natural frequencies were investigated by using the CBC ambient data alone. Clinton (2004) describes this method in more detail. Table 2 presents the resonant frequencies determined by this analysis. Because the translational fundamental and first overtone frequencies are very close, which is unusual for typical structures, it is possible some dynamic feature of the building is not appreciated in this analysis. Ideally, further instrumentation and a forced vibration test are needed to confirm the dynamic properties of the Broad Center listed in the table.

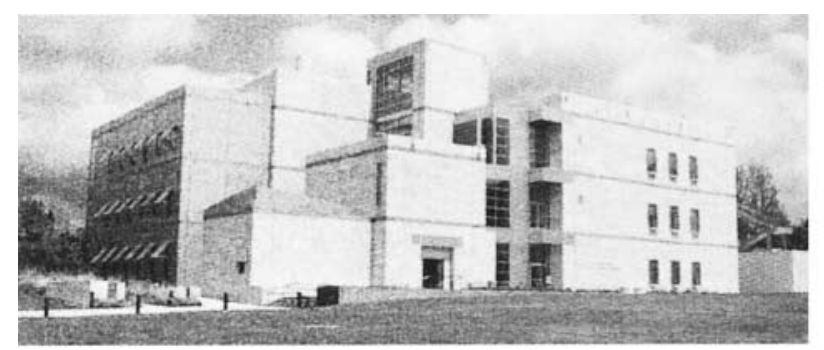

(a) View from S-W

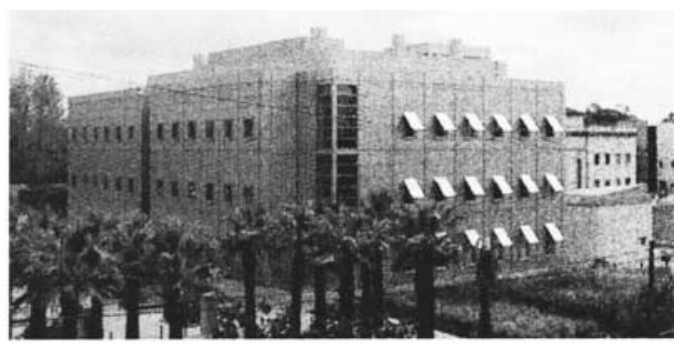

(b) View from $\mathrm{N}-\mathrm{W}$

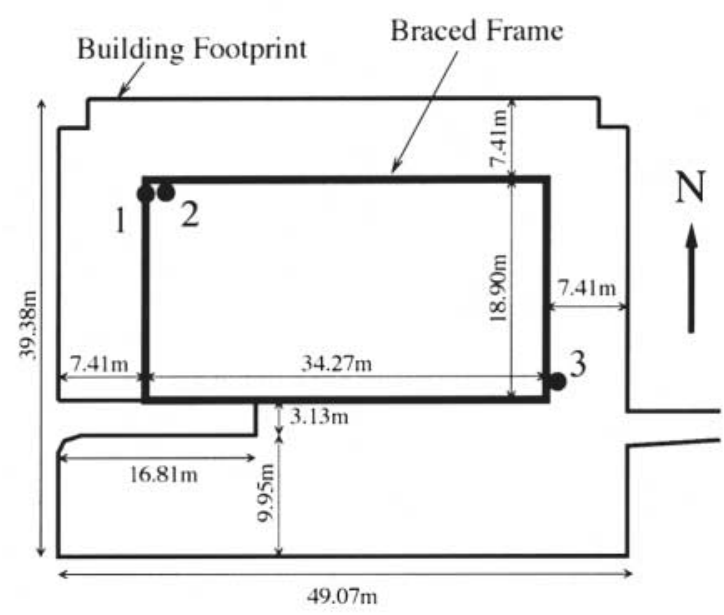

(c) Schematic Plan View

Figure 5. Broad Center. (a) View from the southwest. (b) View from the northwest. Structural core of the unbonded-brace frame is located below the parapet wall visible on the roof. (c) Schematic plan view showing placement of strong-motion sensors. 1 is on the first floor; 2 and 3 are located on the roof. 


\section{S. Wilson Avenue, USGS Office (GSA)}

GSA is a 24-bit SCSN station with a triaxial EpiSensor accelerometer located in the basement of the two-story wood-frame house (used as USGS Pasadena offices). GSA data are often used as a reference station for data from the Millikan Library and Broad Center. The station, operating since July 2000, is approximately $150 \mathrm{~m}$ due west of the Millikan Library, and about $200 \mathrm{~m}$ south-southwest of the Broad Center.

\section{Robinson Building (CRP)}

CRP is a 24-bit SCSN station, located about $18 \mathrm{~m}$ below grade, in the unused Solar Telescope pit of the Robinson Building. It houses a high-gain broadband (Guralp CMG-1) and a strong-motion (Tokyo-Sokushin velocity sensor VSE$355 \mathrm{G} 3$ ) instrument. It is the only station on campus with a high-gain digital instrument permanently deployed. It has been operational since March 2003 and is about $75 \mathrm{~m}$ southwest of Millikan Library.

\section{The Athenaeum (CAC)}

SCSN station CAC is a 19-bit K-2 datalogger with a triaxial accelerometer deployed at the Athenaeum. Located in the basement, CAC occupies the same site as the old analog Athenaeum/Caltech station that has recorded earthquakes since the 1960s. Data are continuously telemetered to the SCSN/SCEDC, but because the information is only 19bit, only events that trigger on the network are permanently stored in the SCEDC.

Continuous and triggered data from these (and all other) SCSN stations may be obtained from the SCEDC at www.data.scec.org. Triggered data from some of the events recorded by the USGS-Caltech array on Millikan Library is available through the National Strong Motion Program at nsmp.wr.usgs.gov.

\section{Analysis of the Continuous Data Streams}

As discussed in the preceding section, two buildings on the Caltech campus. Millikan Library and the Broad Center, have continuous data from instruments located on their upper floors available through the SCEDC. These data streams can be used to analyze the evolution of each building's natural frequencies over the life of these stations, and at other interesting timescales. The natural frequency changes are correlated with weather data from the JPL Weather Station. This is the nearest digital continuously monitored weather station, and it is located $8.5 \mathrm{~km}$ north of the Caltech buildings at the Jet Propulsion Lab. Data are available from the start of continuous data storage from MIK, up to the end of November 2003. This includes 2.5 years of data for MIK, and 10 months for $\mathrm{CBC}$, which started recording in midFebruary 2003.

The JPL weather station logs data every second; the channels used for comparison are rainfall (cumulatively measured per day, millimeters), wind gusts (meters per second), and temperature (degrees Celsius). Subsequent plots present only total rainfall, maximum wind gusts, and the maximum and minimum temperatures.

\section{Entire Station Duration, MIK and CBC}

Figure 6 is a spectrogram plot for the entire history of the station MIK, alongside JPL weather data. The three individual spectrogram subplots are centered about each of the east-west, north-south, and torsional fundamental frequencies. Figure 7 is a similar spectrogram for the history of station CBC. Because the natural frequencies at $\mathrm{CBC}$ are not well determined, individual spectrogram subplots are presented for each of the east-west and north-south channels, over a wide range of frequencies that encompass the observed spectral peaks.

Each spectrogram is made by dividing the acceleration time series into lengths of time (a slice) and taking the fast Fourier transform (FFT) of this time window. The magnitude of the FFT is then represented by a color contour along the $y$ axis at the time on the $x$ axis to which the FFT corresponds (the midpoint slice time). Plotting this for each slice leads to the composite spectrogram. In Figures 6 and 7, the FFT length is $1 \mathrm{hr}$ long, and there is no time overlap between slices. Each FFT has also been first smoothed over a frequency of $0.002 \mathrm{~Hz}$ and then decimated to a sampling frequency of about $0.001 \mathrm{~Hz}$. In these figures, the acceleration amplitude scaling is linear for both MIK and CBC, with upper and lower bounds arbitrarily set to prevent unusual highs, such as the 22 February 2003 Big Bear earthquake, from swamping the color bar.

Because the three fundamental frequencies of Millikan Library are well separated and of large magnitude, the hourly peak in the FFT can be traced over time, as seen in Figure 8 . Here the average of all the peaks is determined, and the deviation from this average is plotted. The daily average of the FFT peak is plotted as a thick line, with the hourly FFT peak plotted as a thin line. The timing of small earthquake excitations and forced vibration testing of the structure are highlighted by vertical bars. These are the source of the obvious large deviations from the mean.

Figure 8 shows considerable variation in natural frequencies over 2 years. In particular, note the sensitivity of the fundamental east-west and torsional modes to rainfall, as evidenced by the large shifts during the winter months, when storms with several days of rainfall are a regular occurrence in southern California. These rain events are infrequent during the summer months. The north-south mode is not as sensitive to the rainfall and, in general, has smaller short-term deviations than the east-west and torsional modes. There is also a steady and unusual rise in the three fundamental frequencies during the spring of 2003, from April to July 2003. This occurs at the same time as a change in usage of three midlevel floors of the library (third, fourth, 

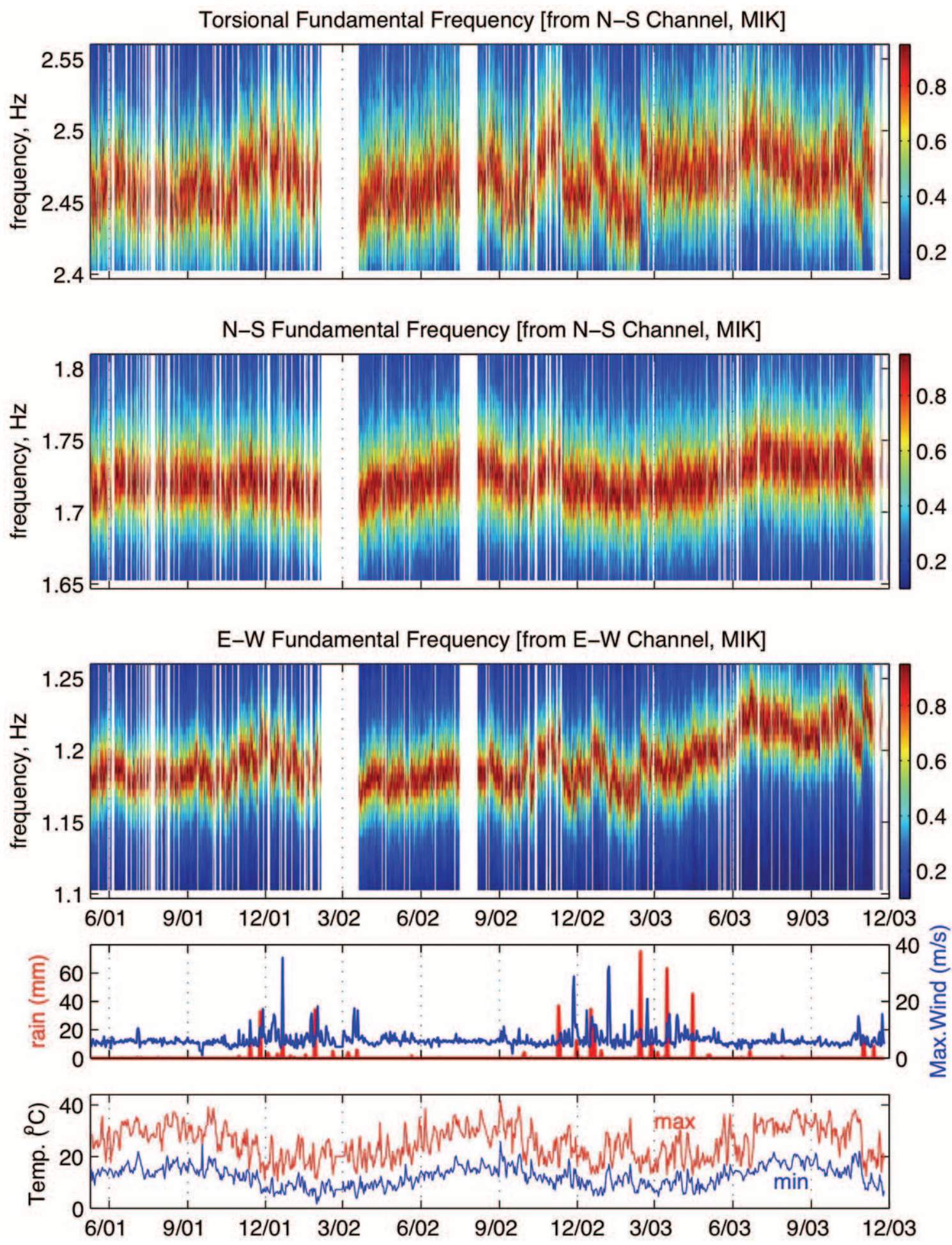

Figure 6. Spectrogram of natural frequencies as observed at MIK, May 2001 through November 2003. Spectrogram composed of 1-hr time windows, each scaled so maximum is 1 and plotted with linear color bar. Weather data are from JPL weather station $(\Delta=8.5 \mathrm{~km})$. Vertical breaks in data are due to days with data glitches or no recorded data. Tick marks on $x$ axis correspond to first of the month labeled underneath. The peaks in natural frequencies are observed to wander over the course of the 2.5 years. No long-term correlation with temperature is observed, though rain causes temporary lengthening of natural frequency. 

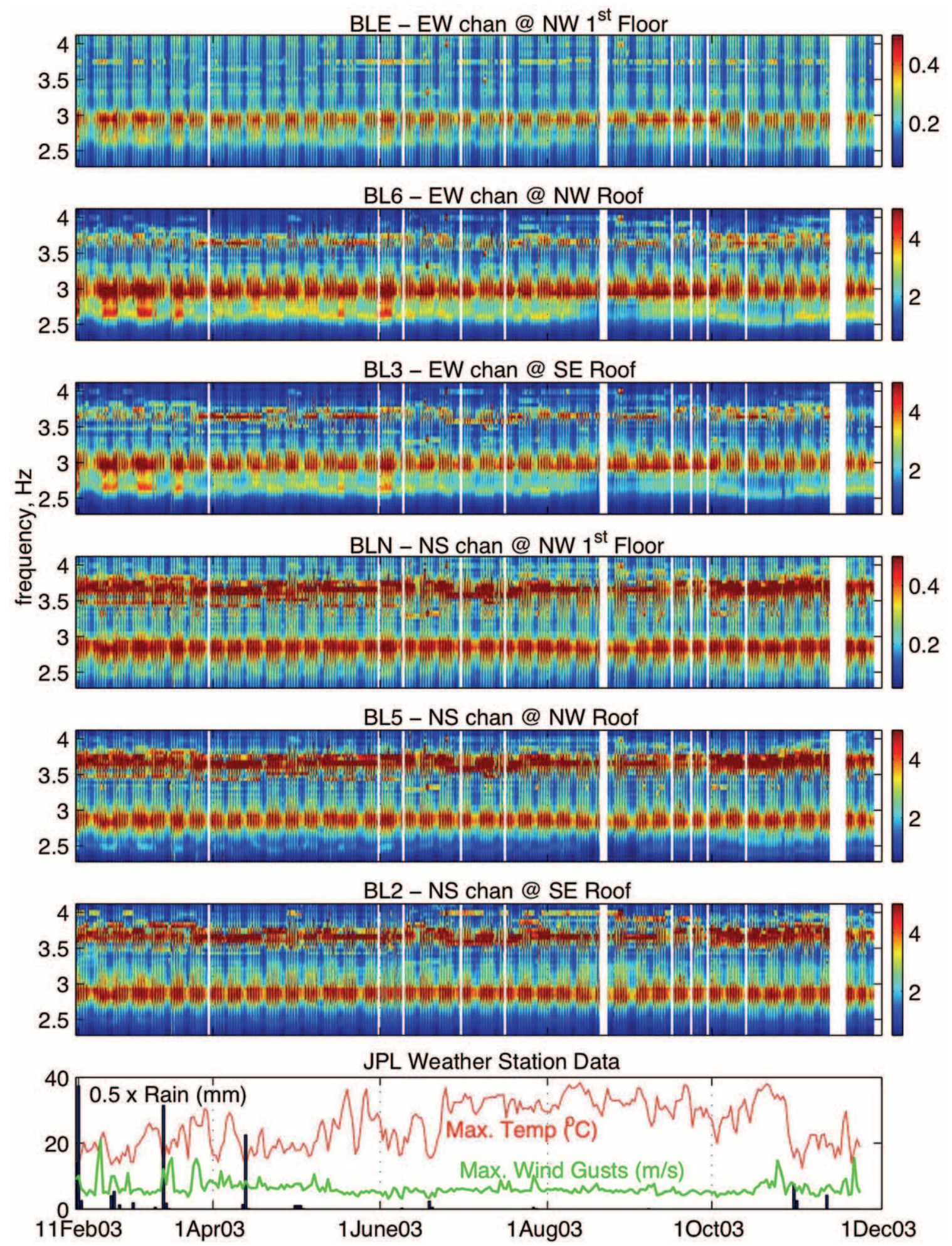

Figure 7. Spectrogram of all six horizontal channels at station $\mathrm{CBC}$, the Broad Center, February 2003 through November 2003. One-hour spectrogram windows, no scaling, linear color bar. Sharp red horizontal lines are due to machine noise in the building. Natural frequencies are represented by the broad peaks, near $2.6 \mathrm{~Hz}, 3.0 \mathrm{~Hz}$, and $3.6 \mathrm{~Hz}$, for the east-west channels, and near $2.4 \mathrm{~Hz}, 2.8 \mathrm{~Hz}$, and $3.6 \mathrm{~Hz}$ for the north-south channels. Notice the 7-day noise cycle with relative quiet on the weekends. 


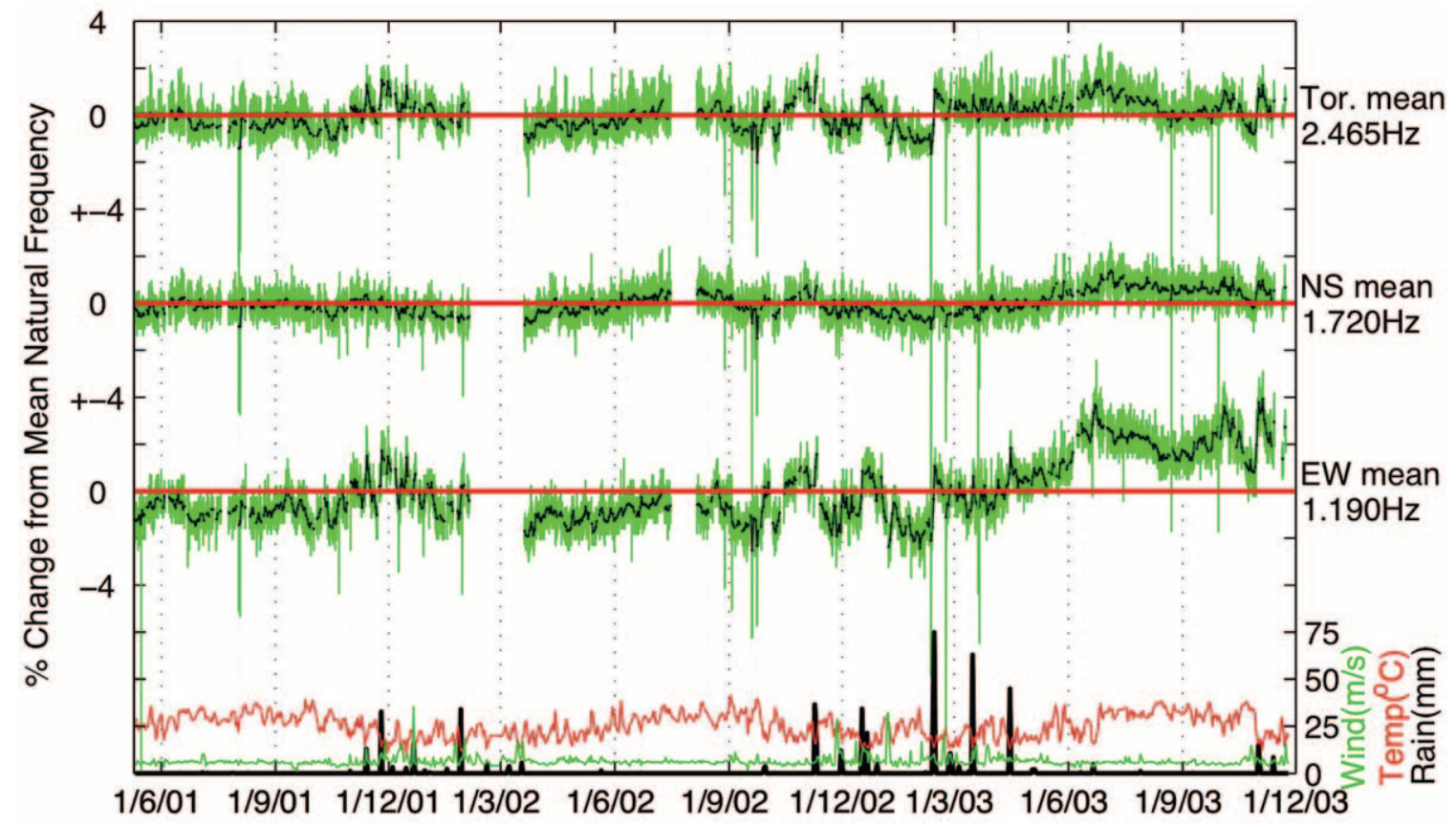

Figure 8. Deviation from the mean natural frequency for the three fundamental frequencies at MIK, May 2001 through November 2003. Fundamental frequencies for each hourly FFT are picked from the peaks in Figure 6, then the deviation from the average is determined. The hourly peak is shown in the thin green line for each frequency; the thick black line tracks the daily average. The thick red horizontal line is the average frequency. Daily rainfall (black), maximum wind gust (green), and maximum temperature (red) from JPL are plotted at the bottom. Vertical blue dashed-dot and red dashed lines indicate days with forced vibration shaking of the library, and earthquakes with motions exceeding $2.5 \mathrm{~cm} / \mathrm{sec}^{2}$ at station MIK, respectively, which produce large deviations from the mean (Earthquakes: 9/9/01, M 4.2 Beverly Hills, $7 \mathrm{~cm} / \mathrm{sec}^{2}$; 30/10/01, M 6.1 Anza, $2.8 \mathrm{~cm} / \mathrm{sec}^{2}$; 3/9/02, M 4.8 Yorba Linda, $5 \mathrm{~cm} / \mathrm{sec}^{2}$; 22/2/03, M 5.4 Big Bear, $18 \mathrm{~cm} / \mathrm{sec}^{2}$ ) Note: forced vibration with full weights generates $8 \mathrm{~cm} / \mathrm{sec}^{2}$ at north-south fundamental mode.

and fifth), from housing library volumes to providing office space. The books were removed during the summer of 2002, with little apparent change in the natural frequencies. However, the construction of partition walls for the new offices in the spring and summer of 2004 coincides with the gradual rise of about $4 \%$ in east-west natural frequency. The rise is less pronounced in the north-south and torsional modes. The natural frequency of a building is proportional to the square root of its stiffness, so an increase of $4 \%$ in natural frequency is equivalent to an increase of $8 \%$ in modal stiffness. It is surprising that such a large increase in stiffness can be attributed alone to the installation of partition walls in three floors, which only rise up to the false ceiling.

Discounting this recent lengthening trend, the following maximum variation for the daily average over the past 2 years are observed:

\begin{tabular}{llcl}
\hline & East-West & North-South & Torsion \\
\hline Min & $1.155 \mathrm{~Hz}$ & $1.71 \mathrm{~Hz}$ & $2.44 \mathrm{~Hz}$ \\
Max & $1.215 \mathrm{~Hz}$ & $1.74 \mathrm{~Hz}$ & $2.55 \mathrm{~Hz}$ \\
Variation & $0.06 \mathrm{~Hz}$ & $0.03 \mathrm{~Hz}$ & $0.10 \mathrm{~Hz}$ \\
& $5.1 \%$ & $1.7 \%$ & $4.4 \%$ \\
\hline
\end{tabular}

Figure 7 presents the first 10 months of data recorded at CBC. Table 2 indicates the suspected natural frequencies of the building. Because these modes have not been well determined from a forced vibration test, a range in frequencies from 2.4 to $4.1 \mathrm{~Hz}$ is presented for the north-south and east-west channels separately. There is significant machine noise, characterized by the heavy horizontal red and yellow lines, near the natural frequencies at $3.65 \mathrm{~Hz}$ (torsional), $2.81 \mathrm{~Hz}$ (north-south) and $3.01 \mathrm{~Hz}$ (east-west). Apparently, these frequencies are being driven by the machine noise from within the building, so subtle shifts in their frequency over time would not be easy to interpret.

The two lowest north-south and east-west frequencies, near $2.43 \mathrm{~Hz}$ and $2.67 \mathrm{~Hz}$, respectively, are not near any machine noise and do seem to exhibit temporal changes similar to those seen in Millikan Library. Clinton (2004) presents additional spectrogram plots that focus on these lower frequencies for all the horizontal channels. From Figure 7 , these frequencies exhibit large variations in signal strength over the period, with significant variation in the natural frequencies themselves. For the first 6 months, there is periodic variation, with a period of the order of 2 weeks. 
After this, the predominant period of variation is much longer, on the order of months. The lowest east-west frequency seems to vary from $2.55 \mathrm{~Hz}$ in mid-October to $2.72 \mathrm{~Hz}$ in early February, a variation of $\sim 6.5 \%$. The lowest north-south frequency is of smaller amplitude than the lowest east-west mode and thus is harder to observe above the ambient noise and is only clearly visible on the northwest roof channel, BL5. It varies from $\sim 2.40 \mathrm{~Hz}$ in mid-October and $\sim 2.52 \mathrm{~Hz}$ in early May, a variation of $\sim 4.9 \%$. This north-south mode appears to disappear in late August and in mid-October drops to $2.4 \mathrm{~Hz}$ for several weeks, coinciding with a large drop in the east-west lowest mode. Rainstorms, such as in early February and early November, clearly raise these resonant frequencies in a manner similar to what is observed in Millikan Library. The spectrograms also have a strong daily and weekly cycle, as much of the machinery is turned off during the nights and weekends.

\section{Winter Storms-MIK}

The temporal variations at MIK (Fig. 8) can be explained in part by correlation with the rainfall data from the nearby JPL Weather Station. This is most clear from the winter of 2002/2003. During this season, heavy winds and rains were recorded. Each rainfall event prompts an immediate rise in the natural frequencies, which is largest in the east-west and torsional modes. After a storm, in the absence of other unusual excitation (such as windstorm, forced vibration test, or earthquake), a gradual recovery (on the order of about a week) of the frequencies to near the prerainfall levels is observed.

Figure 9 is a close-up of the period, including the most severe storm of the period investigated, when over $100 \mathrm{~mm}$ of rain fell during 2 days in early February. This event caused a rapid and immediate rise of about $3 \%$ for the eastwest and Torsional natural frequencies, with a slow decay toward prerainfall levels over a 10-day period.

Figure 10 shows a spectrogram of the east-west fundamental and first overtone frequencies over the same period, February 2003. An obvious rise in frequency of $\sim 3 \%$ is observed in the second mode, with a similar return toward prerain frequencies as shown by the fundamental mode.

\section{Santa Ana Winds-MIK}

Strong winds can also influence the building, though they are usually accompanied by rainfall, which dominates the library's response. Between October and February, dry easterly Santa Ana winds can affect the Pasadena area. In Figure 11a, an example of such an intense Santa Ana windstorm (with no rainfall) is presented. The Library shows a sudden, significant drop in all the fundamental frequencies, in particular, the east-west mode, which drops by about $3 \%$. Amplitudes of the fundamental modes increase by about an order of magnitude during the windstorm, and the torsional mode increases about half as much. Immediately after the event, the stiffness returns to near pre-event levels. This ob- servation is consistent with the drops in natural frequency associated with increasing the weight in forced vibration tests, which also increases the amplitude of excitation.

\section{Diurnal Variation and High Temperatures-MIK}

Figure $11 \mathrm{~b}$ shows a typical example of the building response during hot weather, when there is significant daily variation of at least $1 \%$ for all three fundamental frequencies. This is likely due to both the changing weather conditions and the daily building usage cycle. The air conditioning in the building is turned off between the hours of 12 a.m. and 4 a.m. when the library is closed, so the elevators are also not in use. During the evening, the natural frequencies drop, and, during the day, they increase again. On particularly hot days (such as 1 and 2 September, 2002, in Fig. 11b), where temperatures reach $40^{\circ} \mathrm{C}$ ), there are higher frequency peaks. On cool, overcast and rainy days (such as in Fig. 9), this diurnal variation is not as extreme. It is also clear that the torsional mode is more sensitive to temperature than the translational modes; this mode shows large increases in frequency above about $30^{\circ} \mathrm{C}$, whereas the other fundamental frequencies only show frequency increases at temperatures nearing $40^{\circ} \mathrm{C}$. Maximum daily variations can be as large as $3 \%$.

These frequency increases during the day seem to be associated with thermal expansion of the concrete, but as the amplitudes of the ambient motion also increase by an order of magnitude during the day, this is inconsistent with the general observation that natural frequencies drop as amplitude increases. For these amplitude levels, the thermal effects are larger than the excitation amplitude effects. Figure $11 \mathrm{~b}$ includes hourly amplitudes of the FFT peaks, which show this increased noise level in the building associated with the working-hours usage of the building. In the evenings and weekends the building has less noise as the air conditioning and other machinery, such as the elevator, are not in constant operation.

There does not appear to be any long-term trend associated with seasonal trends in temperature, as evidenced from Figure 6.

\section{5.4 22 February 2003 Big Bear Sequence}

The moderate $M 5.4$ Big Bear earthquake occurred at 4:19 a.m. PST on 22 February 2003, at a distance of $120 \mathrm{~km}$ from the campus. At the time of the event, the stations GSA, MIK, and CBC all were operational, and the USGS-Caltech array in Millikan Library also triggered. However, the basement channels and two channels recording the north-south directions on the east side of the building did not recover data because of the refurbishment of parts of the building.

\section{Millikan Library}

USGS Triggered Data. Figure 12 shows the time series for all the east-west channels in the Millikan Library triggered 


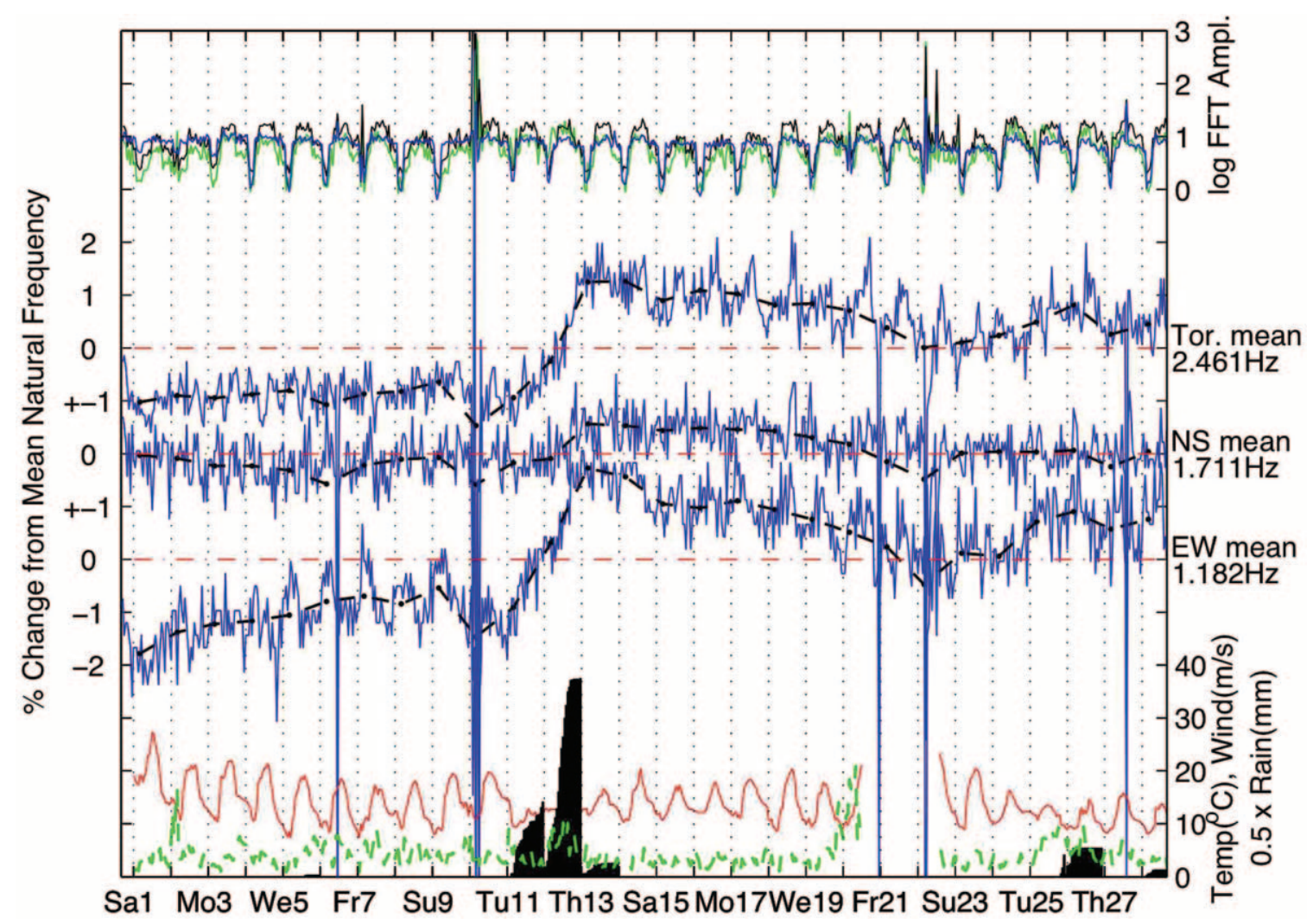

Figure 9. Deviation from the mean for the natural frequencies of Millikan Library, February 2003, which includes a major rainstorm. In the center of the plot, for each of the three natural frequencies, the horizontal red lines are the monthly average, the black lines are the daily average percent deviation from this mean, and the blue lines are the hourly percent deviation from mean. At the bottom of the figure, the black-bar data are the cumulative hourly rainfall (re-zeros at midnight). The red line is the maximum hourly temperature, and the green is the wind gust. On the top of the figure are each natural frequency amplitude for the hourly FFT peak. The rainfall coincides with a very sharp rise in natural frequencies in the east-west and torsional modes, followed by a slow return toward prerainfall levels. Dashed vertical lines represent the start of each new day (12 a.m. PST). Frequency spikes are due to instrument glitches $(6,21$, and 27 February), vibration testing (10 February), and the Big Bear earthquake (22 February). FFT peaks fall at night and on weekends. No major increase in excitation amplitude occurs during rainfall events not associated with high winds.

array. The FFTs of these records centered about the eastwest modes are also shown; the east-west fundamental frequency is at $1.06 \mathrm{~Hz}$ and the east-west first overtone is at $4.55 \mathrm{~Hz}$. These values are approximately $7 \%$ lower than the corresponding natural frequencies determined during forced vibrations (see Table 2). Further, the fundamental frequency is $11 \%$ below the ambient natural frequency of $1.19 \mathrm{~Hz}$ (Fig. 13a) just before the earthquake. and the second mode is $6.2 \%$ below the pre-earthquake ambient frequency of $4.85 \mathrm{~Hz}$ (Fig. 10).

Note that the amplitude of the peak at $4.55 \mathrm{~Hz}$, which is identified as the second mode, is small at the seventh, eighth, and ninth floors; the time series between 8 and $12 \mathrm{sec}$ is rich in this frequency in the other floors. The mode shape for this frequency (see Fig. 12) shows these floors are near a nodal point, and this explains why it is difficult to identify the second east-west mode using the nineth floor MIK data alone. This is seen in the small magnitude broad second mode peak in Figure 10.

Little excitation of other higher order modes was observed in the earthquake data, including the fundamental torsional mode, so no examination of their wander is attempted. Also note that no significant energy is present at the resonant frequencies in the reference site GSA record.

MIK Continuous Data. The continuously recording strongmotion channels from the ninth floor of Millikan provide an excellent opportunity to look at the wander in the Library's natural frequencies before, during, and after the mainshock, and to observe how the structure regains its stiffness after minor shaking.

Figure 13a shows a spectrogram for the three funda- 

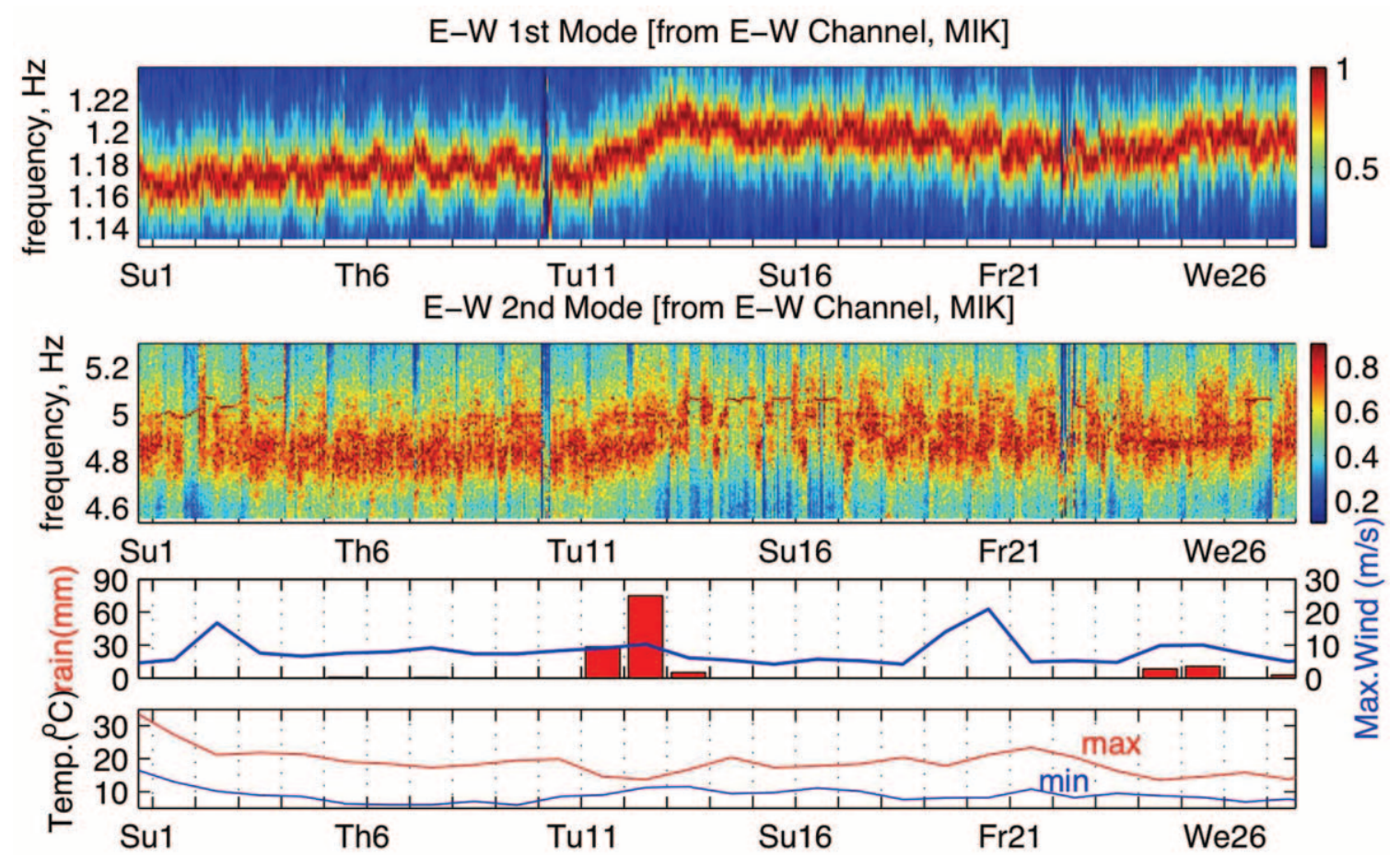

Figure 10. Spectrogram of fundamental and first overtone for east-west mode during February 2003, a time of heavy rainfall. One-hour spectrogram windows, scaled by the maximum value, linear color bar. JPL weather on bottom. Note correlation between rises in both natural frequencies and heavy rainfall.

mental frequencies and the second east-west mode frequency for a 60 -min period around the mainshock. FFTs are taken over a 30 -sec period with 15 -sec overlap. Although the frequency resolution is poor because of the short FFT length, during the earthquake the previously relatively stable frequencies all decrease by about $10 \%$. Recovery from the earthquake to pre-earthquake levels appears to be almost instantaneous once the shaking has diminished. Aftershocks also shorten the frequencies, but by a lesser amount, commensurate with the smaller amplitudes of motion-for example, in Figure 13b, a $M 4.1$ aftershock occurs at $170 \mathrm{~min}$, with a measurable decrease in frequency.

Figure 13b presents a spectrogram similar to Figure 13a for a 3-hr period around the same event, with FFTs taken over a 5-min period with a 4-min overlap. This provides improved resolution in the frequency domain, although resolution in the time domain is significantly diminished. The increased length also provides evidence that, though the natural frequencies are shortened a small amount in the immediate aftermath of an event, after about an hour, there is no perceptible difference between the pre- and postevent natural frequencies.

For this level of excitation, the structure regains its stiffness within minutes. This is in contrast to evidence (Udwadia and Trifunac, 1974) that suggests Millikan Library takes weeks or months to return to near pre-earthquake levels after undergoing strong motion. However, this observation is based on a minor shaking, whereas their observations were from San Fernando earthquake motions, which caused rooftop accelerations over 10 times greater than the Big Bear event. Thus, extrapolation of the Big Bear result to the largest shaking that the building has been subjected to may not be valid. Note though that the work by Udwadia and Trifunac was based on two tests performed a few weeks and 22 months after the San Fernando earthquake. In these tests the observed decrease in the east-west natural frequency from the pre-earthquake measurement was $18 \%$ and $12 \%$, respectively. Subsequent data (Clinton, 2004) suggests the permanent change from the original natural frequency of $1.45 \mathrm{~Hz}$ was about $12 \%$. Udwadia and Trifunac (1974) show FFT segments from the tail of the strong-motion record (about $80 \mathrm{sec}$ after the initial triggering) that indicate the building is already returning to the pre-earthquake state. The differences in measurements may be explained by the many changing variables such as weather and test parameters and may not be due to long-term "healing" of the structure.

\section{Broad Center}

The continuous data from the Broad Center (CBC) provide another dataset for analyzing the effect of a small earthquake on the natural frequencies of a structure.

Figure 14 is a $3-\mathrm{hr}$ spectrogram of the three horizontal east-west channels of CBC, with FFTs with a length of 5 min. These spectrograms have each FFT scaled to a maximum value of 1 , so during the earthquake, the torsional 

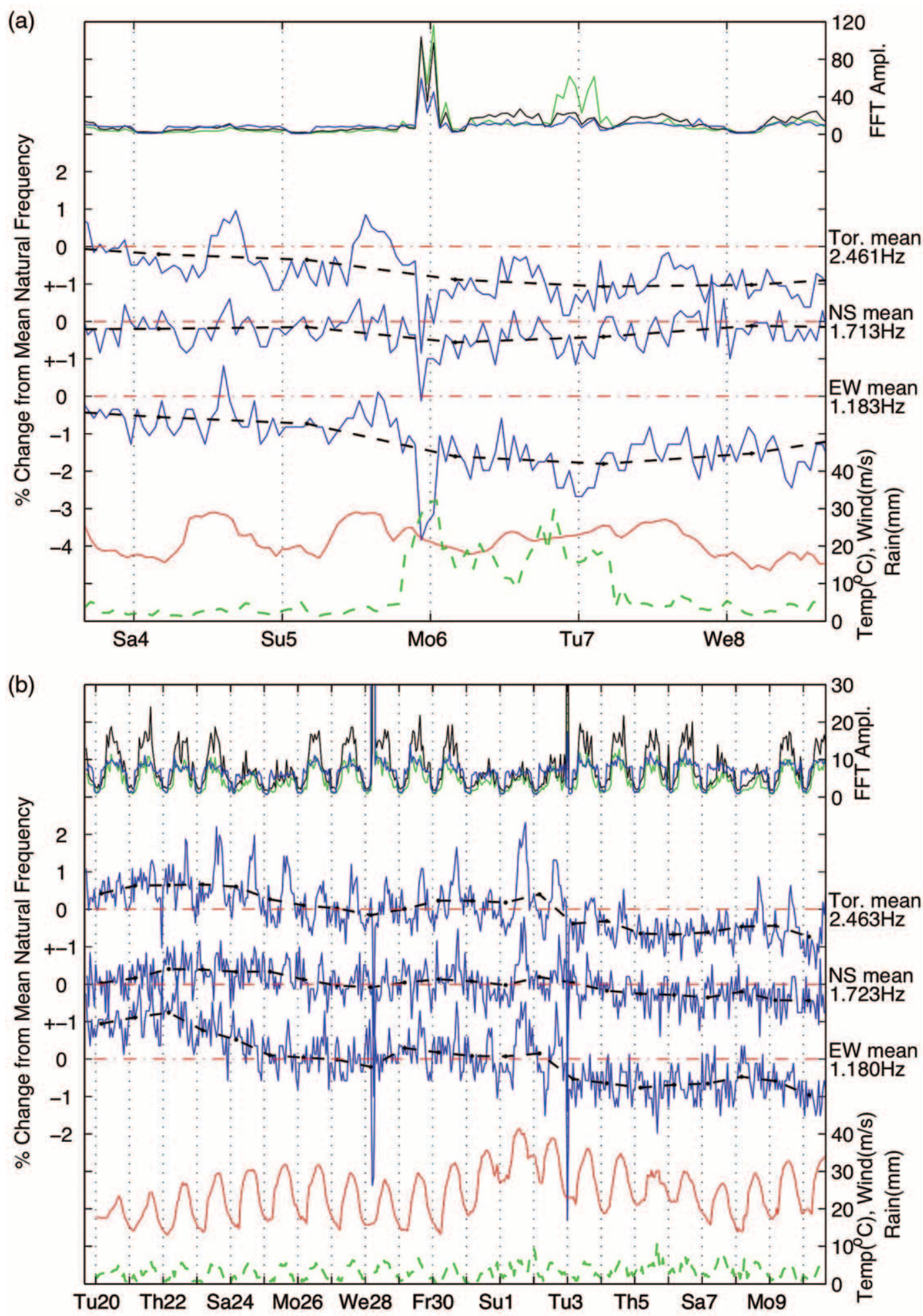

Figure 11. As Figure 9. (a) For a 5-day period in January 2003, with a particularly intense wind storm (no rainfall). The natural frequencies of the Library dramatically shorten for the duration of the most intense windstorm, most notably in the east-west direction, but also significantly for the north-south and torsional modes. The smaller windstorm in the evening of January 6 appears slightly shifted in time from the response; this may be due to variations in the winds between the Library and the weather station at JPL. The mean frequencies are for the whole month of January. (b) For a 22day period, late August to early September 2002. Typical daily variation during the summer months. Note correlation of rise in all three natural frequencies during hottest days. 26 August, vibration testing; 3 September, $M 4.8$ Yorba Linda Earthquake. 

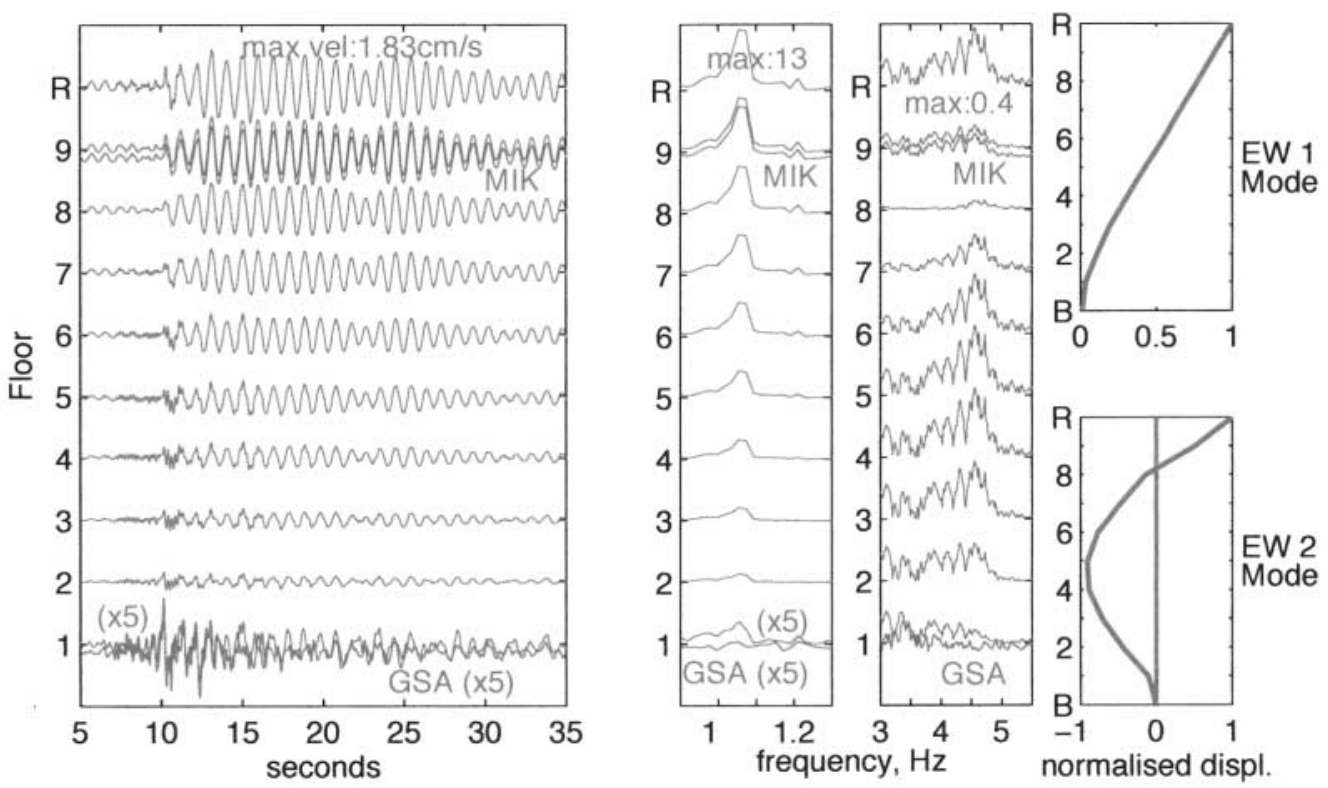

Figure 12. East-west components of USGS-Caltech Array in Millikan Library, $M$ 5.4 Big Bear earthquake: velocity time series and FFT. Includes floors 1-9 and roof of Millikan Library as well as GSA. ("free-field" site) and MIK (on ninth floor of Millikan Library), plotted underneath the first and ninth channels. FFT plots are centered around the fundamental frequency $(1.06 \mathrm{~Hz})$ and first overtone $(4.55 \mathrm{~Hz})$ for the east-west direction. Also included are the two east-west mode shapes as identified from forced vibrations (Bradford et al., 2004).

mode is not visible as the translational modes are predominantly excited. For each channel, a wide frequency band of acceleration spectra is plotted; a narrow band of displacement spectra centered on the fundamental frequency is underneath. Displacement spectra accentuate the energy in this frequency relative to the higher frequencies, and because these two fundamental frequencies are not driven by electrical or mechanical noise, fluctuations in frequency can be more easily observed.

During the earthquake, the natural frequencies all change considerably - it is not clear exactly which frequencies correspond to the values observed during the shaking, because all three frequencies are so close together. It is clear that immediately after the earthquake, the frequencies return to their pre-earthquake levels. Similar changes are seen in the north-south channels (Clinton, 2004).

\section{A Linear Transfer Function Solution?}

A simple method of modeling structural response to ground motions is to convolve the fundamental mode building response with a nearby reference recording of ground motion. There are obvious problems with this linear method during strong motion, because the fundamental frequency varies with excitation levels. Nonetheless, during small excitations, a linear response is expected.

This example attempts to model the known east-west displacements at MIK using a convolution of the east-west acceleration ground motion at GSA with an impulse response of a single degree of freedom (SDOF) model representing the east-west fundamental frequency of Millikan Library. Amplitude amplification is determined by using the participation factor of the first mode, assuming a mass matrix of equal floor mass, and modes shapes as determined from the forced vibration tests. This convolution gives the relative displacement of MIK to GSA, so the ground displacement at GSA is added. A constant damping ratio of $1.63 \%$ is employed, which is the value determined from the forced vibration tests (Bradford et al., 2004).

Figure 15 presents examples of the results for two recent earthquakes. Figure 15a presents data from the 18 June 2003 $M 2.0$ Pasadena earthquake (a foreshock of a $M 2.6$ event $20 \mathrm{~min}$ later), $5 \mathrm{~km}$ from Caltech, which had a maximum acceleration of $1.2 \mathrm{~cm} / \mathrm{sec}^{2}$ at MIK. Figure $15 \mathrm{~b}$ presents data from the 22 February 2003 M 5.4 Big Bear earthquake, $119 \mathrm{~km}$ from Caltech, which had a maximum acceleration of $22.6 \mathrm{~cm} / \mathrm{sec}^{2}$ at MIK. Figure 15a shows that the model is improved if the ambient SDOF, derived from ambient data immediately before the event, is used instead of the default forced vibration value. For this event, a default SDOF representing the second east-west mode is also included to help model the high-frequency response. In Figure 15b, where the behavior of Millikan during the stronger motion is modeled, both the ambient and forced SDOF give a poor fit. In this case, the natural frequency has moved far from the ambient levels (as seen in Fig. 12) and is best modeled using a natural frequency as determined from the strong-motion records $(1.06 \mathrm{~Hz})$. Though the character of the strongest mo- 

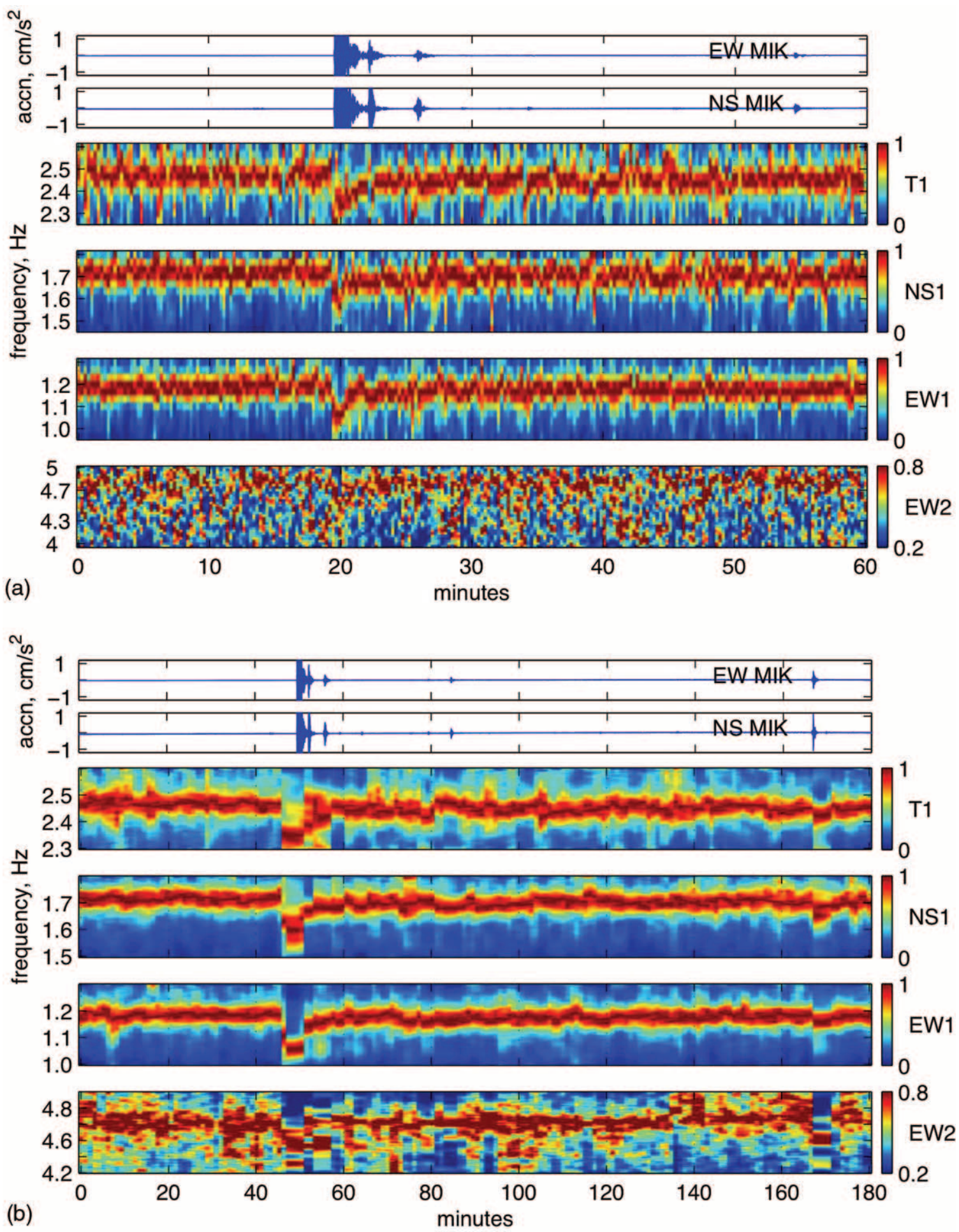

Figure 13. Acceleration data and resulting spectrograms for MIK from 22 February 2003. M 5.4 Big Bear earthquake occurs at 12:19 UTC. Maximum acceleration $=19.3$ $\mathrm{cm} / \mathrm{sec}^{2}$ north-south, $10.9 \mathrm{~cm} / \mathrm{sec}^{2}$ east-west. Spectrograms are set around the four natural frequencies. (a) 12:00-13:00 UTC, 30-sec-window spectrograms, with slices shifted by $15 \mathrm{sec}$. The natural frequencies shorten considerably during the mainshock shaking and aftershocks. Analysis of long-term behavior, especially that of the second mode east-west, is limited by poor resolution due to short FFT length. (b) 11:30-14:30 UTC, 5-min window spectrograms, with slices shifted by 1 min. After shaking has dissipated, over this time window it is clear there is no perceptible long-term shortening of the fundamental frequencies due to the earthquake. The event at $168 \mathrm{~min}$ is a $M 4.1$ aftershock. 


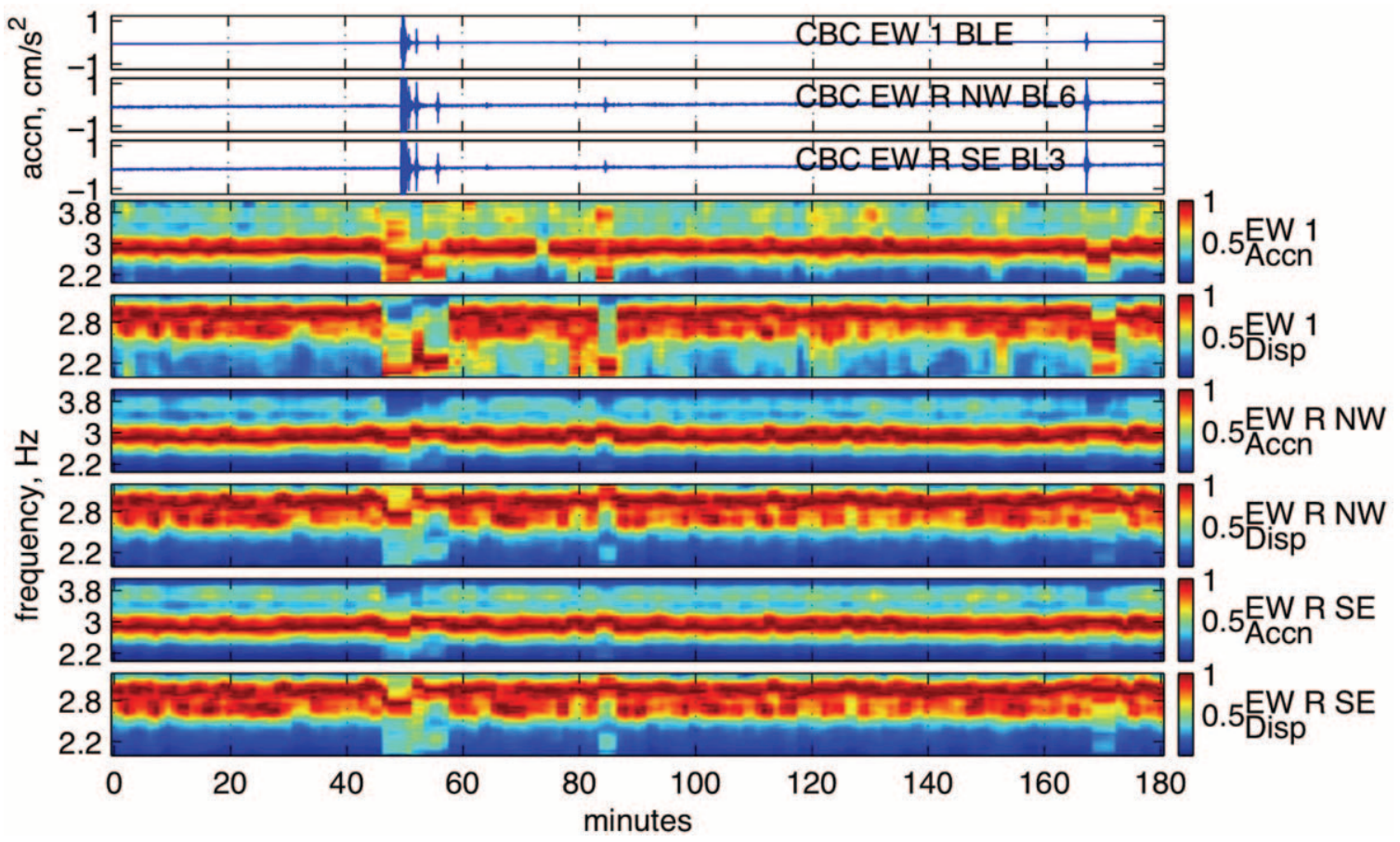

Figure 14. Acceleration data and spectrograms from $\mathrm{CBC}$ east-west channels, 11:30-14:30 UTC. Five-minute window slices, each shifted by 1 min. There are two spectrograms for each east-west channel; the first is a broad frequency range from acceleration data showing all identified modal frequencies; the second is a frequency band around the first mode using displacement data, which accentuates the behavior of the only mode without nearby machine noise (see Fig. 7). M 5.4 Big Bear earthquake occurs at 12:19 UTC. Maximum acceleration $=14.8 \mathrm{~cm} / \mathrm{sec}^{2}$ at BL6, northwest Roof. During the event, the fundamental frequencies shorten considerably. After shaking, over this time window there is no perceptible long-term shortening of the fundamental frequencies due to the earthquake.

tions is well modeled by this last SDOF, the low-amplitude $P$-wave and coda motions are not well modeled, suggesting the natural frequency seems to be evolving rapidly, as the excitation amplitude changes. These motions are small, and are certainly within the expected the linear response of the building, yet a single natural frequency cannot predict the motions of the building.

Current engineering practice has a single natural frequency assigned to the building, usually not even derived from experimental testing, but from formulae in the relevant design code. This natural frequency is assumed constant for a wide range of ground motions. The results presented in this article, and elsewhere in the literature (Trifunac, 1999), suggest that natural frequencies are not constant, even for weak motions.

\section{Conclusions and Comment}

The data collected from the continuous monitoring of structures supports the thesis that the dynamic behavior of structures is determined by several external factors on very different timescales.

In the case of Millikan Library, there is significant wan- der in the translational and torsional natural frequencies of the structure. It is evident that, in addition to this wander, the method used to determine the natural frequency at a point in time also introduces some variability, because the amplitude of excitation of the building is different for each method. Ambient motion, forced vibrations, and earthquake data will have very different excitation amplitudes.

To the first order though, there has been a significant permanent reduction in natural frequencies for the Millikan Library in the 36 years of its life, $22 \%$ east-west and $12 \%$ north-south. The natural frequencies of a structure are proportional to the square root of the mass and inversely proportional to the square root of the stiffness. The system mass has not changed significantly during the life span, so this change in natural frequency corresponds to a major decrease in system stiffness.

The large permanent frequency drops appear to be caused almost entirely by strong motions from moderate nearby LA Basin earthquakes. In particular, the 1971 San Fernando $M$ 6.6 earthquake had the largest effect, with permanent drops of $17 \%$ east-west and $7 \%$ north-south. For the east-west direction, the accelerations of this earthquake were not subsequently exceeded, and there were no more 
(a)

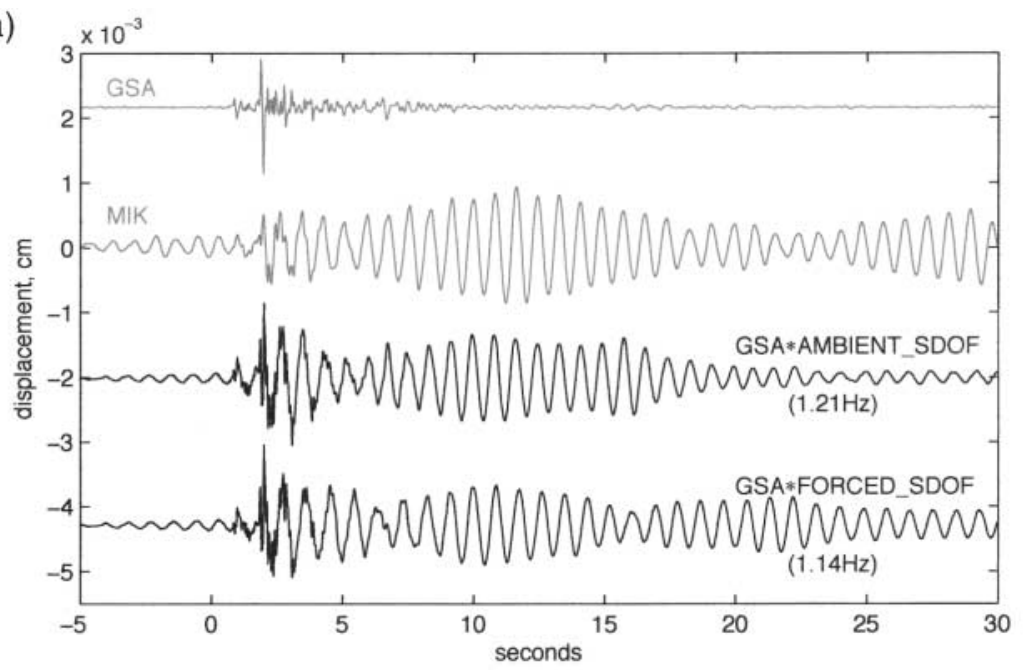

(b)

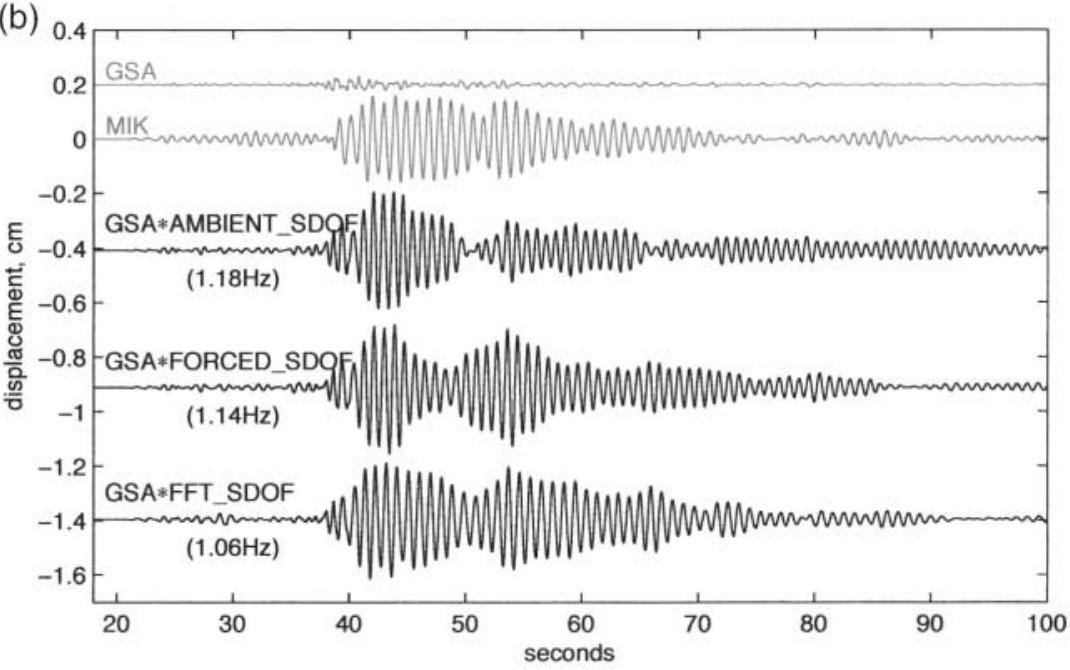

Figure 15. Prediction of MIK east-west motions using GSA east-west as input motion. Motions recorded at GSA are convolved with an impulse response at a particular frequency. Ambient_SDOF uses the fundamental frequency as determined from FFTs of pre-event data, Forced_SDOF uses the fundamental frequency as determined from forced vibration tests. (a) $M 2.018$ June 2003 Pasadena earthquake $(\Delta=5 \mathrm{~km})$. A nonyarying secondmode SDOF response is included for both ambient and forced models to include the high-frequency components of the motions. During this very small amplitude motion, the natural frequency determined using the ambient data models the observations at MIK better than the forced vibration result. (b) $M 5.4$ 22 February 2003 Big Bear earthquake $(\Delta=$ $119 \mathrm{~km})$. Neither the Ambient_SDOF or Forced_SDOF response model the MIK observation well. Another model, FFT_SDOF, with natural frequency at $1.06 \mathrm{~Hz}$, as determined by the FFT peak of the strong-motion record is included. This leads to a somewhat improved model of the observed motion. Clearly, even during the moderate shaking generated from this relatively small and distant earthquake, a linear building model is inappropriate. A model that can have evolving natural frequencies will best represent the observed motions. large permanent frequency drops. However, in the northsouth direction, the San Fernando roof-top acceleration of $341 \mathrm{~cm} / \mathrm{sec}^{2}$ was exceeded with a recording of $534 \mathrm{~cm} / \mathrm{sec}^{2}$ during the 1987 M 6.1 Whittier Narrows event. This caused a further permanent drop of $4 \%$.

During the strong shaking, these moderate local events are shown to almost instantaneously shorten the frequencies by more than $20 \%$ without apparent structural damage. Because only triggered data are available for large motions, there is no clear evidence of the time frame for stiffness recovery. Continuous data from small earthquake motions, such as from the 2003 M 5.4 Big Bear earthquake, reduce the ambient natural frequencies by up to $10 \%$ during the motion, with a full recovery within minutes. Similar observations are documented for the fundamental translational modes of the Broad Center.

Smaller transient excitations also reduce the natural frequencies, such as forced shaking tests (by up to $7 \%$ with full shaker weights) and small earthquakes. Heavy rain increases the east-west fundamental and first overtone and the torsional fundamental frequencies by up to $3 \%$ in a matter of hours, with little effect to the north-south fundamental frequency. This increase in frequencies occurs even though the amplitude of building motion is increased during storms, increases in displacement amplitudes on the roof typically lead to a decrease in the natural frequencies. When strong winds occur in the absence of rainfall, all the natural frequencies can drop by up to $3 \%$. The diurnal variation is of the order of $1-2 \%$. On a day with a high temperatures near $40^{\circ} \mathrm{C}$, rising temperatures raise all the natural frequencies by a further $1-2 \%$.

For transient changes due to extreme weather, the recovery time can vary significantly. Any changes arising from wind and temperature only seem to last as long as the excitation, but for rain events the Library and the Broad Center slowly return to the pre-event fundamental frequencies over about 1 week.

On a longer timescale, changing building usage can be responsible for large changes in the frequencies. Construction of partition walls to provide office space in three midlevel floors of the library over 4 months is shown to coincide with an increase in frequencies during this same period- 
the east-west fundamental frequency is particularly affected ( $4 \%$ increase over this period). Note that a $4 \%$ increase in natural frequency corresponds to an $8 \%$ increase in stiffness for the whole structure. The construction of the partition walls was preceded by the removal of the entire book collection from these three floors, which did not have an observable effect on the natural frequencies.

The sources of all these observed wanders are not well understood. The different observed effects may be due to soil-structure interaction, super-structure non-linearities, or a combination of both.

For the particular case of the Millikan Library, Chopra (1995) suggests that the changes in the dynamic behavior of the building during strong motion and weak forced shaking are associated with "cracking and other types of degradation of the so-called non-structural elements." This mechanism does not account for the observed changes due to weather events.

The increases in natural frequency, and thus apparent increase in stiffness, during rain events may be caused by saturation of the soil. If the soil is dry before the event, perhaps saturation could also cause swelling of the soil, producing extra pressure against the sides of the foundations, reducing the amount of rocking and translation of the building. This attenuation of the base motions would lead to a stiffer system. Unfortunately, this does not explain why the east-west mode is most affected by the weather, yet the north-south mode, with $30 \%$ of the roof displacement for this mode shape being due to basement rocking (appendix 3 in Bradford et al., 2004), is not affected as much. The component of rocking in the east-west mode is not well characterized by recent studies, for example, Bradford et al. (2004). Further, the gardens surrounding the building are heavily watered throughout the year, so they are likely to be near-saturated year round. Also note that the natural frequencies rise as soon as the rainfall event begins, or even beforehand. This could be because the JPL weather station is $7 \mathrm{~km}$ from Caltech, toward the mountains, and may receive its rainfall slightly delayed to the Caltech campus.

Stiffness changes in the superstructure during rain events should also be considered. Wetting of the concrete could potentially lead to expansion of the window/wall panels and thus stiffen the east-west moment frames. This would explain why the east-west mode is most affected by rainfall. Slow recovery of pre-event stiffnesses would be determined by the drying process, which would be slow in the winter rainy season. Cycles of heating and cooling could have the same effect on the superstructure, but as heat is radiated quickly, this effect is transient.

Both mechanisms explain the observation that large rains not preceded by other events cause the largest increases in natural frequency. Rainfall events that closely follow the large storm sequences do not cause major changes themselves, because the soil or concrete is already in an expanded state.

The loss of natural frequency during heavy winds is consistent with the observations from previous investigators that, as the amplitude of forced vibrations increases, the frequency drops. This is also consistent with the drop in frequency with increasing amplitude of earthquake excitation, from weak motions to strong motions, presented here.

The rise in frequency during hot weather is likely due to a stiffening of the frame from thermal expansion of the concrete. All three fundamental frequencies are similarly affected by this. During the day, the ambient excitation is an order of magnitude larger than at night (when elevators and air conditioning are not in use, and the building is unoccupied), and so, in the absence of this thermal expansion, the natural frequencies during the day would be expected to decrease.

The dramatic reduction in stiffness during moderate shaking could also be due to nonlinear soil-structure interaction, because there is no appreciable structural damage to Millikan during strong shaking. Measurement of pore-water pressures near the Library would help resolve the validity of this hypothesis. Another explanation would be that the bolted wall panels on the north and south sides of the structure, which provide resistance in the east-west direction, may loosen during stronger shaking. A single crack has been observed along pour lines on the north-south elevator core shear wall between the basement and the first floor, and between the first and second floors. Analysis of strain over the length of these cracks during different motions may also give insight into whether the loss of stiffness observed in the building may be due to rocking about these cracks. There are potentially other cracks in the elevator core in the eastwest walls, but these walls are covered by architectural features and cannot be investigated.

The wandering in the natural frequencies is significant for the engineering community. In engineering practice, a linear structural behavior is assumed for ambient and small motions, but this is clearly not the case. Further, as real-time structural health monitoring is becoming a reality, these unexpectedly large variations in the fundamental parameter of building response need to be accounted for in any damage assessment. Structural damage usually results in a loss of structural stiffness, which is characterized by a drop in the natural frequency. However, these observations of wandering natural frequencies due to ambient and small motions should serve to caution the community that not all changes in natural frequency can be attributed to structural damage. This phenomenon needs to be accounted for by any damage assessment methodology with any claims of robustness.

\section{Acknowledgments}

We appreciate the comments from Mihailo Trifunac and an anonymous reviewer who improved the quality of the manuscript. We thank Arnie Acosta and Erdal Safak for their help with obtaining data from the USGS array at Millikan Library. We also thank SCEC's UCSB Portable Broadband Instrument Center (PBIC) for use of their portable seismometers and the JPL Weather Station for the weather data. John Hall, Georgia Cua, and the members of Caltech's Structural Monitoring Group, especially Jim 
Beck and Wilfred Iwan, provided extremely helpful feedback and review. This research has been funded through TriNet. We thank the TriNet staff for carrying out the implementation of the TriNet system. Funding for TriNet has been provided by Federal Emergency Management Agency (FEMA) and the California Governor's Office of Emergency Services (OES) through the Hazards Mitigation Grant Program established following the 1994 Northridge earthquake. The required 25\% cost-sharing is provided by California Institute of Technology, California Trade and Commerce Agency, Caltrans, IDA H.L. Crotty, Verizon California, Donna and Greg Jenkins, Pacific Bell/CalREN, Southern California Edison, Sun Microsystems Inc., Times Mirror Foundation, and others. Funding has also been provided by the USGS from their special Northridge funds. The Southern California Earthquake Data Center (SCEDC) is also funded by the Southern California Earthquake Center (SCEC).

The support of the Puerto Rico Strong Motion Program (PRSMP) at the University of Puerto Rico at Mayaguez (UPRM) in the completion of the project is gratefully appreciated.

\section{References}

Alves, W., and J. F. Hall (2003). Nonlinear modeling of Pacoima Dam using earthquake recordings to assess the effect of topographic nonuniformity in ground motion. Technical report, Data Utilization Report, California Strong Motion Instrumentation Program (CSMIP).

Beck, J. L., and E. Chan (1995). Comparison of the Response of Millikan Library to San Fernando and Whittier Narrows Earthquakes. Unpublished report, California Institute of Technology, Pasadena, California.

Bradford, S. C., J. F. Clinton, J. Favela, and T. H. Heaton (2004). Results of Millikan Library forced vibration testing. Technical report, California Institute of Technology, http://resolver.caltech.edu/CaltechEERL:EERL-2004-03 (last accessed January 2006).

Camelo, V. S. (2003). Dynamic characteristics of woodframe buildings, Ph.D. Thesis, California Institute of Technology.

Chopra, A. K. (1995). Dynamics of Structures-Theory and Applications to Earthquake Engineering. Prentice Hall, New York, 409-414, 514515.

Clinton, J. F. (2004). Modern digital seismology—instrumentation, and small amplitude studies for the engineering world, Ph.D. Thesis, California Institute of Technology.

Foutch, D. A. (1976). A study of the vibrational characteristics of two multistory buildings, Ph.D. Thesis, California Institute of Technology, Earthquake Engineering Research Laboratory, Pasadena, California.

Foutch, D. A., and P. C. Jennings (1978). Foundation response of a ninestory reinforced concrete building, Bull. Seism. Soc. Am. 68, no. 1, 219-229.

Foutch, D. A., J. E. Luco, M. D. Trifunac, and F. E. Udwadia (1975). Full scale, three dimensional tests of structural deformation during forced excitation of a nine-Story reinforced concrete building, in Proc. U.S. National Conf. on Earthquake Engineering, Ann Arbor, Michigan, 206-215.

Hudson, D. E. (1962). Synchronized vibration generators for dynamic tests of full-scale structures, Technical report, Earthquake Engineering Research Laboratory, California Institute of Technology, Pasadena, California

Jennings, P. C., and J. H. Kuroiwa (1968). Vibration and soil-structure interaction tests of a nine-Story reinforced concrete building, Bull. Seism. Soc. Am. 58, no. 3, 891-916.

Kuroiwa, J. H. (1967). Vibration test of a multistory building, Ph.D. Thesis, California Institute of Technology, Earthquake Engineering Research Laboratory, Pasadena, California.

Levine, M. B., J. L. Beck, W. D. Iwan, P. C. Jennings, and R. Relles (1988), Accelerograms recorded at Caltech during the Whittier Narrows earthquakes of October 1 and 4, 1987: a preliminary report, Technical report, California Institute of Technology, http://resolver.caltech.edu/ CaltechEERL:1988.EERL-88-01 (last accessed January 2006).

Luco, J., M. Trifunac, and H. Wong (1987). On the apparent change in dynamic behavior of a 9-story reinforced-concrete building, Bull. Seism. Soc. Am. 77, no. 6, 1961-1983.

Luco, J. E., H. L. Wong, and M. D. Trifunac (1986). Soil-structure interaction effects on forced vibration tests, Technical Report 86-05, University of Southern California, Department of Civil Engineering, Los Angeles, California.

McVerry, G. H. (1980). Frequency domain identification of structural models from earthquake records, Ph.D. Thesis, California Institute of Technology.

Teledyne-Geotech-West (1972). Post earthquake vibration measurements Millikan Library, Technical report, Teledyne Geotech West, Monrovia, California.

Trifunac, M. (1999). Period formulas for concrete shear wall buildingsdiscussion, J. Struct. Eng. ASCE 125, no. 7, 797-798.

Trifunac, M., and S. S. Ivanovic (August, 2003). Analysis of drifts in a seven-story reinforced concrete structure, University of Southern California Report CE 03-10.

Trifunac, M. D. (1972). Comparisons between ambient and forced vibration experiments, Earthquake Eng. Struct. Dyn. 1, 133-150.

Udwadia, F. E., and M. D. Trifunac (1974). Time and amplitude dependent response of structures, Int. J. Earthquake Eng. Struct. Dyn. 2, 359378.

Puerto Rico Strong Motion Program

Department of Civil Engineering and Surveying

University of Puerto Rico at Mayaguez

Mayaguez, Puerto Rico 00681

jclinton@uprm.edu

jclinton@ecf.caltech.edu

(J.F.C.)

Department of Civil Engineering

Division of Engineering and Applied Science

California Institute of Technology

Pasadena, California 91125

case@ caltech.edu

heaton_t@ caltech.edu

(S.C.B, T.H.H.)

Lockheed Martin Aeronautics Company

Palmdale, California 93599

javier@gps.caltech.edu

(J.F.)

Manuscript received 18 March 2005. 